\title{
INTRACRANIAL IRRITATION IN THE NEWBORN : IMMEDIATE AND LONG TERM PROGNOSIS
}

\author{
BY \\ W. S. CRAIG \\ From the Department of Paediatrics and Child Health, University of Leeds
}

(Received for Plblication December 19, 1949)

Neonatal morbidity no less than neonatal mortality remains an outstanding paediatric problem. Numerous investigations have studied the frequency with which stillbirths and neonatal deaths are due to intracranial trauma. Much less that is reliable is known concerning the subsequent progress of infants who survive intracranial birth injury. A number of published studies deal with the clinical diagnosis of intracranial birth trauma, but only a small number deal with prognosis and an even more limited number with permanent sequelae. This paper summarizes clinical observations made in the course of a follow-up survey of 593 infants who were diagnosed as suffering from intracranial irritation following birth and who were subsequently kept under observation for periods varying from six months to five years or more.

\section{The Literature}

Diagnosis. Huenekens (1923) draws attention to the way in which the study of diagnosis of cerebral haemorrhage in the newborn has been neglected, and comments upon the frequency with which in fatal cases doubtful diagnoses are entered on death certificates when in reality the cause of death has been cerebral haemorrhage. He allows that symptoms arising from birth trauma are often elusive and recommends that indefinite symptoms lacking explanation should always lead to suspicion of cerebral haemorrhage. Capon (1922) holds the view that symptoms of intracranial trauma are readily recognizable except in the 'slightest case.' Fleming (1931) on the other hand is of the opinion that diagnosis of intracranial haemorrhage in the newborn during life is extremely difficult.

Basing his opinion on a retrospective study of cases verified at necropsy as having suffered from the late effects of cerebral birth injury, Benda (1945) considers that cerebral damage can be recognized in most cases immediately after birth, and in all cases within a few weeks, or at most, months after birth. The view is expressed by Ehrenfest (1922) that although'small haemorrhages may not give rise to any symptoms, signs may develop which are strongly suggestive of intracranial trauma but which because of their indefinite character or rapid disappearance, may be attributable to 'concussion of the brain' or 'fleeting oedema' rather than to haemorrhage. He considers that immediate prognosis is especially grave where convulsions recur at short intervals, and that it is hopeless when a paralytic state follows a convulsive phase.

There is a considerable measure of agreement in the descriptions given of symptomatology. Munro (1928) lists as important a poor cry, hypertonicity, cyanosis, disinclination to nurse, a tense fontanelle, apathy, abnormal respirations, 'irritable c.n.s.', and nystagmus. Tyson and Crawford (1931) attach importance to fretfulness and cyanosis aggravated by manipulation. The intermittent nature of cyanotic attacks is stressed by Clein (1929). Particular importance is attached by Capon (1922) to disinclination to suck. Fleming (1931) considers that a bulging fontanelle is an unusual finding. Sharpe and Maclaire (1924) found changes of the fontanelle variable and inconstant. Whereas Fleming (1931) considers muscular rigidity as having diagnostic value, Capon (1922) states that paralysis is not usually a prominent feature. Sharpe and Maclaire (1924) are of the opinion that while some infants with intracranial birth trauma present severe symptoms, the clinical picture in others is slight and in some may be normal.

Many writers favour lumbar puncture as a routine method of diagnosis. Capon (1922) urges that there should be no delay in carrying out the procedure in suspected cases. Fleming (1931) considers that cerebrospinal fluid which is pigmented or uniformly stained with crenated red cells is probably the most reliable finding in diagnosis. His view is shared by Sharpe and Maclaire (1924) who found blood-stained fluid in $13 \%$ of 100 babies who represented consecutive deliveries and were lumbar-punctured within 24 to 48 hours after birth. Tyson and 
Crawford (1931) and Munro (1928) attach importance to evidences of increased intracranial pressure, but the former states that he obtained a blood-stained fluid in one of every five apparently normal newborn babies who were lumbar-punctured. On the other hand Benda (1945) declares categorically that a blood-stained spinal fluid is encountered so often after birth that no significance is to be attached to the finding if it is the only one in an otherwise normal child. The opinion concurs with that of Smith (1934). As a result of clinicopathological investigations Craig (1935 and 1938) concluded that success in securing early, reliable diagnosis is dependent not on a study of individual signs alone, but on fecognition of signs (or their absence) in conjunction with physiognomical observations and observations on the behaviour pattern of the infant.

Immediate Prognosis. In the opinion of Ehrenfest (1922) the immediate effect of intracranial birth trauma is dependent upon the extent and location of the resulting haemorrhage. According to Capon (1922) the immediate prognosis is favourable if the infant survives the fifth day of life, but caution is called for where convulsions and twitching movements are present and where there is bulging of the anterior fontanelle. Fleming and Morton (1930) emphasize that the outlook in the case of a premature infant is especially poor. Ford (1944) describes how in cases which recover early symptoms may disappear either slowly or rapidly and how, in contrast, some infants remain in a precarious state for a number of weeks. The same writer comments on the way in which apparent paralysis of one or more extremities associated with rigidity, twitching movements, or flaccidity may disappear. In some cases disappearance is final and complete while in others evidence of true paralysis may appear many months later. Munro (1930) is of the opinion that a 'hypertonic baby has more than an even chance' while a ' cyanotic baby has less than an even chance' to live. He considers that prognosis is worst where cyanosis is associated with apathy and abnormal respirations.

In the experience of Ford (1944) relapses are most likely to occur about the sixth or seventh day of life. Sustained improvement is most slow in the case of premature infants. Craig (1938) draws attention to the occasional recurrence of haemorrhage from a healing tentorial tear with fatal results in the second week following delivery. He considers that signs arising from intracerebral haemorrhage are liable to violent aggravation after the tenth day of life.

Ultimate Prognosis. Ford (1944) refers to the lack of agreement concerning the nature of sequelae which may result from cerebral birth trauma in the newborn, and Munro (1928) comments on the lack of evidence concerning the end results of the different forms of treatment of infants who survive. Accepting that severe cerebral injury can give rise to delayed sequelae Ehrenfest (1922) expresses the view that it has not been established that similar results may follow intracranial birth trauma of limited degree. At the same time he points out that doubts on this last point are in some measure due to the frequency with which the early signs of cerebral birth injury are missed. Various attempts have been made to correlate the effects of birth injury with subsequent physical or mental disabilities. Some few writers have conducted follow-up surveys of infants diagnosed as having survived cerebral birth injury. Other writers have adopted the reverse procedure and conducted retrospective studies of the birth histories of children examined on account of various forms of handicap.

Munro (1928) records a series of 117 infants suffering at birth from cranial or intracranial damage. Fifty-eight of the infants were discharged from hospital ' relieved or improved.' Trace was lost of ten of these. Of the remaining 48 , four were established as dying from causes related to their cerebral condition, two developed hydrocephalus, and one epilepsy. One of the cases of hydrocephalus suffered from fits. Twenty-four children were normal in all respects at the age of $2 \frac{1}{2}$ years. Munro concludes that residual phenomena can usually be recognized before the first birthday, and always before the end of the second year, and that the most common late result of cerebral damage in the newborn is hydrocephalus associated with either epilepsy or idiocy. Benda (1945) considers that late sequelae are invariably recognizable by the age of 9 months.

In a series of 103 cases of cerebral birth injury reported by Fleming and Mortor (1930) 53 survived the early weeks of life. Of the survivors, five developed mental or physical defects. One of these five patients was considered to be a true case of cerebral diplegia. Fleming (1931) gives asymmetrical paralysis, hydrocephalus and mental deficiency as the most common sequelae. According to Anderson (1945) cerebral palsies are the commonest finding. In Capon's (1922) opinion paralysis is not usually noticed until after the age of 6 months. Roberts (1939) considers that of children surviving cerebral haemorrhage at birth $75 \%$ develop normally and that only a relatively small number develop spastic pareses.

Ford (1944) gives clinical details of 33 cases showing evidence of disabilities which he considers to have resulted from cerebral birth trauma. His 
findings have led him to conclude that hemiplegia is the commonest disability; that monoplegia is common, and that in general any impairment of mental function is slight and not associated with marked personality changes. Ford refers to the occurrence in some cases of athetoid movements, of unilateral cerebellar ataxia, and of rapid growth of the head in the early weeks or months of life. In his experience convulsions are common, and mild palsies sometimes lessen in degree. He describes four cases of double hemiplegia. Striking obesity was a feature of a few of his cases.

Ford considers that ultimate prognosis is not good where the presence of a residual disability has been established. There is always the possibility that a disability may become more obvious with age. Epileptiform convulsions are given by Benda (1945) as one of the commonest results of birth injury in his series of mentally deficient children. He considers that convulsions are of special value in diagnosis because of their relatively early time of onset, and that neurological disorders of a motor and sensory type rank second in significance. Ford emphasizes that the appearance of convulsions may be delayed until 10 or more years after birth. Epilepsy, regardless of the age of appearance, may be associated with mental deterioration and Ford is satisfied makes for a poor prognosis.

Within recent years increasing interest has been focused on the possibility of certain disabilities formerly attributed to birth injury being in fact evidences of developmental errors. This aspect is dealt with by Ehrenfest (1922), Ford (1926 and 1944), Benda (1945), and McGovern and Yannet (1947). There is an increasing tendency to attribute cerebral diplegia to errors of cerebral development. Comparing cerebral palsies with palsies of different aetiology McGovern and Yannet comment upon the high proportion of first born and the smaller average size of head among the former, and upon the advanced maternal age and the increased incidence of prematurity in the latter group. According to Ford (1926) the heads of the diplegic cases are usually either definitely microcephalic or slightly below normal size, whereas meningeal haemorrhage causes rapid enlargement of the head.

Different conclusions were arrived at by Benda (1945) as a result of post-mortem studies on 130 mentally deficient children. His series included 11 cases of children with spastic paraplegia. Of these cases, three conformed to the clinical picture described by Little, and at necropsy the cerebral lesions were only detectable microscopically.

In the opinion of Fleming and Morton (1930) neonatal symptoms of intracranial irritation offer no clue as to the likelihood or otherwise of the development of sequelae. Permanent and complete recovery can follow the most violent neonatal clinical course, and eventual disability may develop in infants who show only slight evidence of stress following birth. Fleming suggests that the occurrence and character of sequelae are determined by the site rather than by the extent of intracranial haemorrhage. Ford (1944) arrived independently at similar conclusions concerning difficulties in the way of accurate long-term prognosis. He draws attention to the scarcity of reliable published information on the subject. Rydberg (1932) found that of 41 children surviving cerebral birth injury only 10 developed normally. Ford does not accept Rydberg's findings as typical and estimates that less than $15 \%$ of infants surviving cerebral birth injury subsequently show evidence of disability.

\section{The Present Investigation}

The General Plan and Scope. The objects of the investigation were twofold. The primary object was clinical study of the subsequent development of infants diagnosed as having survived intracranial irritation at birth. As a secondary objective the investigation aimed at correlating sequelae (where they occurred) with symptoms recorded during the neonatal period, and at applying the findings of that correlation to a study of prognosis in relation to intracranial irritation in the newborn.

Duration. The clinical investigations forming the basis of this paper were begun in March, 1931, and completed in October, 1948. During the period 1938-41 no new cases were added to the series and delay occurred in following up a proportion of the children included in the investigation before 1939.

SOURCES OF MAterial. Children included in the series have been drawn from a variety of sources determined by the place and nature of the writer's work at different times. In the total series of 593 children, 405 were seen in Edinburgh, and the remainder in the Home Counties and Yorkshire. The series includes 529 childern born in maternity hospitals or maternity homes, and 64 born at home. Of those born at home, 37 were removed to hospital shortly after delivery. A proportion of the babies studied in the Home Counties were born in wartime emergency maternity homes intended for normal deliveries only.

Clinical Appraisal. This was concerned with diagnosis during the neonatal period of intracranial irritation and intracranial birth injury, and with recognition at the time of follow-up examination of departures from normal physical and mental development.

Apart from a few exceptions children included in the series were examined by me personally within 
two days of birth. The great majority were first seen within 24 hours of birth and thereafter at short intervals throughout the neonatal period. Particular attention was paid to advising midwives and house surgeons on the clinical signs to be looked for in the early recognition of intracranial irritation. As a result, I was enabled to see many more infants at an earlier stage after delivery than would otherwise have been possible. The suspicions of the resident staff were not always confirmed. Cases included in the present series consist only of those in which a diagnosis of clinical irritation was based on my personal observations.

It was originally intended that children included in the series should be re-examined at the age of 6 months and subsequently at ages approximating to their first, third, and fifth birthdays. This proved impracticable and it became necessary to re-examine children as and when other circumstances permitted rather than according to preconceived age intervals. Large numbers of children were seen at follow-up clinics associated with maternity hospitals. Many others were visited in their own homes. Some were re-examined by arrangement at infant welfare clinics. Follow-up examinations were directed towards a clinical assessment of the child's physical, emotional and mental state. The opportunity of re-examination was taken to review the history of the patient and his family with the object of ensuring that no factor likely to cast doubt on an apparent association of abnormalities with the natal history had been missed. The writer carried out all followup examinations.

RECORDS.- Clinical findings were recorded at the time of all examinations during the neonatal period and on all subsequent occasions. Negative and positive observations were recorded. In every case detailed information was obtained concerning the pregnancy, the labour, maternal health, and family history.

\section{Clinical Criteria}

Intracranial Irritation after Birth. Flagrant evidences of intracranial haemorrhage in the mature newborn child of normal size are not difficult to recognize. Nevertheless the clinical picture presented by the newborn infant with intracranial trauma can readily be masked by the presence of other factors. Where asphyxia of severe degree exists, signs directly attributable to haemorrhage are more difficult to recognize. In the premature infant intracranial damage of severe degree may give rise to surprisingly slight, even fleeting clinical signs. Atelectasis is a frequent, if not almost constant accompaniment of intracranial trauma. The extent to which the clinical features arising from intracranial damage are modified by complicating atelectasis varies. Haemorrhage in certain forms and under certain circumstances may be accompanied by oedema which may involve the meninges or the meninges and brain substance, and which may be more severe in character than the haemorrhage itself.

Invaluable as clinical signs are in contributing to a diagnosis of intracranial birth trauma, final decision as to diagnosis requires to take account of the antenatal history of the mother and the detailed character of the labour considered in relation to the maturity and size of the infant. Inevitably reliability in diagnosis is most difficult to achieve in those cases in which recognizable clinical features are minimal either because they are of themselves slight or because they are masked by the operation of other variable factors, whether related to mother or infant. It was realized at the outset of the investigation that cases presenting minimal clinical signs were of particular importance, and that failure either to recognize them or correctly to interpret their significance might invalidate any general conclusions. It was decided, therefore, to conduct a parallel investigation intended to correlate clinical findings during life with pathological findings after death in newborn infants showing evidence of intracranial haemorrhage at necropsy. The results of this other investigation have already been published (Craig, 1935 and 1938) and provide the basis for clinical diagnosis adopted in the inquiry which is the subject of this paper. The two investigations are to be considered as complementary.

As a further measure intended to favour greater reliability in diagnosis the ante-natal and obstetrical histories of all children provisionally listed for inclusion in this investigation were subjected to a final review. In the few instances where retrospective study of the history and records pointed to the possibility of haemolytic disease of the newborn, to gross atelectasis persistent for reasons not wholly attributable to coincident intracranial irritation, or to haemorrhage no matter how slight from the skin, the mucous membrane or any of the orifices, the case was excluded from the final series. A similar course was adopted in the case of a small number of children born of mothers whose pregnancies had been characterized by abnormal events or experiences, which, no matter how remotely, might have interfered with normal foetal development in utero. Account was taken of known exposure of the mother to infection, maternal illness, and $x$-ray therapy during pregnancy, and of threatened abortion or miscarriage. Any child showing evidence of a developmental anomaly was automatically excluded from the series. Nineteen 
children were eliminated for one or other of these reasons. It is realized that an excessively rigid process of exclusion may have been adopted. Nevertheless it was felt that the main purpose of the investigation could only be achieved if prime importance were attached to the elimination so far as practicable of possible sources of error.

Examination of a specimen of the cerebrospinal fluid has not been considered either necessary or desirable in arriving at a diagnosis. A clear fluid does not exclude the possibility of cerebral haemorrhage any more than a bloodstained fluid is confirmation of the presence of cerebral haemorrhage. Also it is my firm conviction that lumbar puncture is not in the interests of the patient where the signs point to intracranial irritation, provided always that there is no possibility of meningitis.

Late Sequelae of Intracranial Irritation at Birth. An outline of the follow-up procedure adopted has already been given. Any child who at the time of re-examination showed evidence of impaired physical or mental development or concerning whom a history of epilepsy or of abnormal behaviour was obtained, was submitted to a complete physical examination. At the same time, further particulars were sought concerning the family history and the health of previous children, especially of any familial tendency to epilepsy or psychopathic history in connexion with any member of the family. Inquiries were also made concerning any hereditary or familial conditions which might not have been previously disclosed. In the case of those children in whom palsies were found, particular note was made as to whether the paralysis was symmetrical or asymmetrical in distribution; the degree of spasticity associated with the paralysis; and the severity of any mental impairment accompanying the physical handicap. Account was taken of incidental errors of development not previously noted. Cases of microcephaly were excluded. In the final assessment especial importance was attached to evaluation of essentially natal factors.
As in the case of criteria applied in diagnosis during the neonatal period, a policy of rigid exclusion was adopted in the case of any child with whose handicap there appeared to be a possibility of a contributory factor arising from a hereditary background, a familial tendency, a developmental error or disease in the interval between birth and

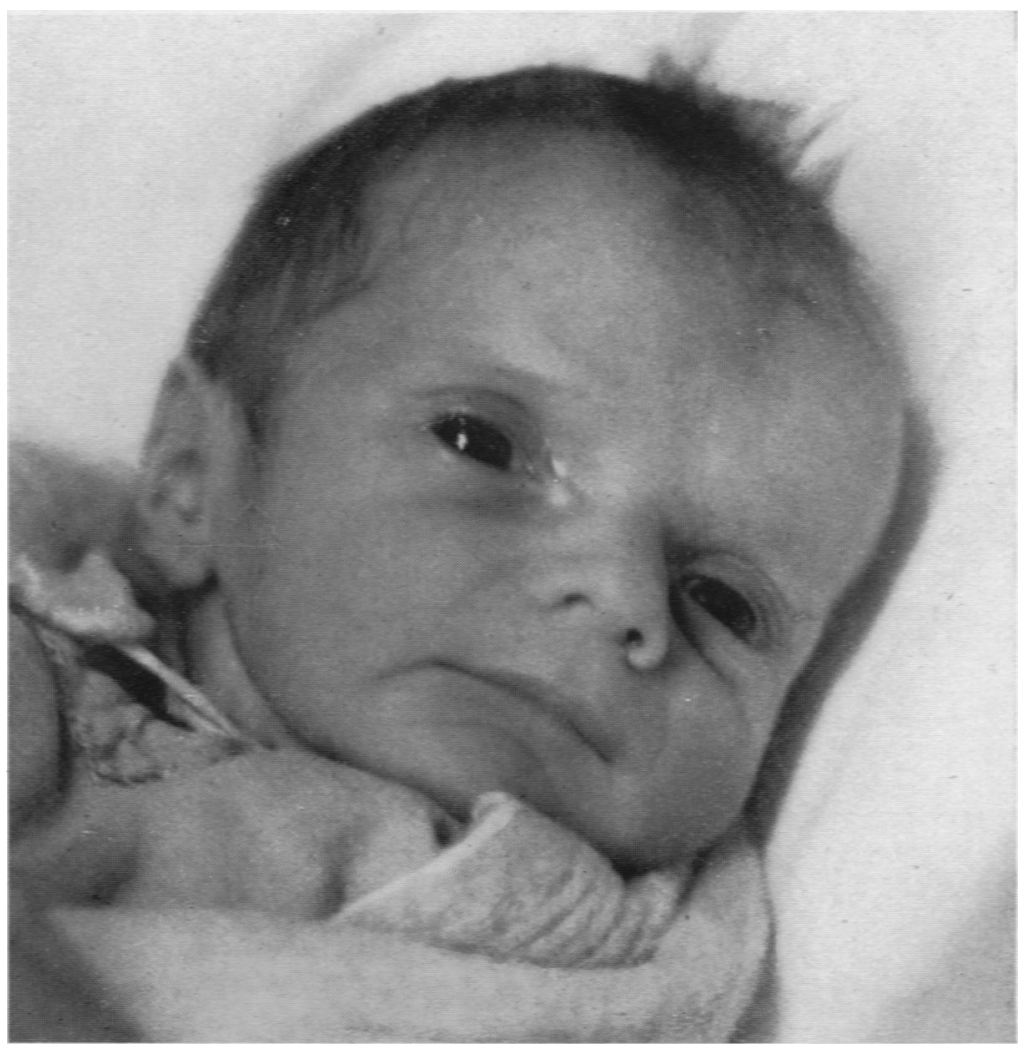

Fig. 1.-Infant aged five days with signs of severe intracranial irritation.

re-examination. Twelve children included in the original survey were excluded from the final series on these grounds.

\section{The Clinical Series and Clinical Observations}

Intracranial Irritation after Delivery. The present series consists of 593 infants who showed evidence of intracranial irritation at some time during the first ten days of life and all of whom lived for not less than six months and were first re-examined about that age. Of the 593 infants, 444 were firstborn infants. Delivery was spontaneous in 261 (including 55 breech presentations), instrumental in 316 , and by Caesarean section in 16 infants. The 316 instrumental deliveries included 36 cases in which there was a breech presentation, and 102 cases 
in which either manual or instrumental rotation of the presenting head had been carried out before delivery. There were 189 premature infants (i.e., infants weighing $5 \frac{1}{2} \mathrm{lb}$. or less); 338 infants born at term; and 66 infants considered to be post-mature.

The cases included in the series are summarized in Table 1.

Cinical Picture in the Earty Days and Weeks of Life. Early in the course of the investigation, attempts were made to group cases according to the probable nature and distribution of the underlying pathological process. It soon became evident that any such grouping might ultimately prove misleading. As a preferable basis for study of prognosis it was decided to consider cases in groups determined by the severity or otherwise of the clinical picture present in the early days. Cases composing the series under investigation have, therefore, been grouped as follows:

(A) Gross or Violent Clinical Signs. Cases in this group include infants showing evidence of gross asphyxia followed by the development of convulsions; unquestionable neck rigidity or actual neck retraction; bulging of the fontanelle and ocular signs; and intense physical and mental restlessness following a phase of inactivity. Constant findings were a strangely anxious expression and a wholly unnatural concentration of gaze giving place at times to a frowning or scowling expression. The frown if not present could often be easily elicited by gently flexing the neck. The awareness, and at times actual alertness, of these infants were more in keeping with an age of several weeks rather than of several days (Fig. 1). Vomiting over a period of a few days was a frequent finding. So also were signs of great exhaustion. In some cases fine tremors and athetoid movements were recognizable. In all cases there was markedly exaggerated response to external stimuli. A slight rise in temperature was common. Pulse and respirations showed variations of all types and of all degrees of severity. It is sometimes stated that a reluctance to take fluids is a feature of severe intracranial damage in the newborn.

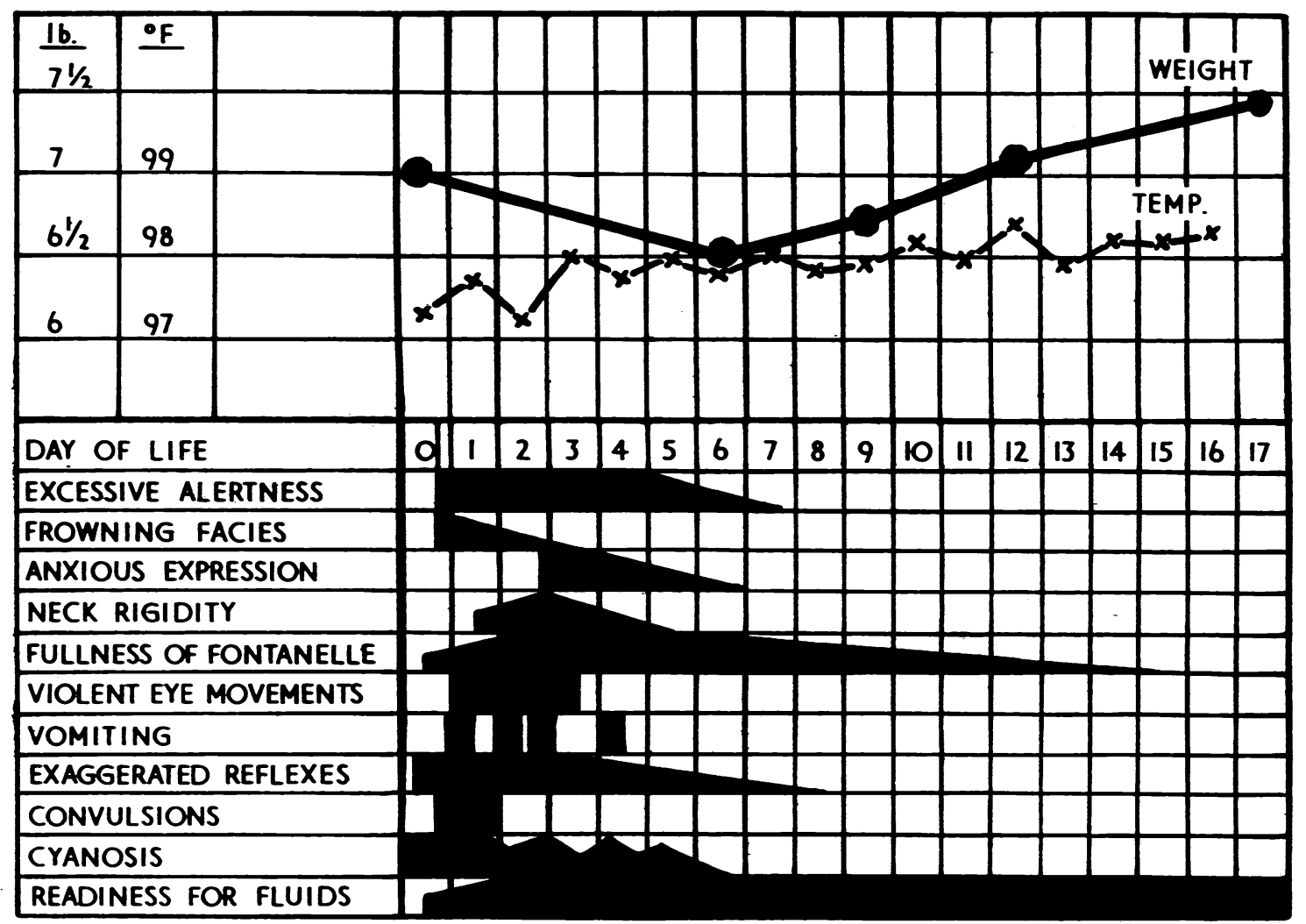

Fig. 2-Diagram of a case showing gross physical signs of intracranial irritation.

Prolonged labour; elderly mother; foetal distress; asphyxia at birth. Spastic paralysis noted at 2 months and confirmed at 3 years. Poor intelligence at 5 years. (Appendix: Case No. 590.) 
While this is the case during such time as severe asphyxia persists, the statement is not in accordance with my own experience, in so far as infants who survive are concerned. These infants are often incapable of indicating their need for fluids, but in the hands of a nurse experienced in handling the ill newborn infant, can, except during periods of convulsive movements, be given the fluid requirements by mouth and without difficulty. As is to be expected, weight progress is interfered with, but not to a serious extent (Fig. 2).

Fifty-three infants in the total series showed gross clinical evidence of intracranial irritation. Of these eight were premature, 36 born at term, and nine post-mature. Delivery was spontaneous in nine, instrumental in 43, and by Caesarean section in one infant. Rotation of the head was carried out before instrumental delivery in 22 instances.

(B) Severe Clinical Signs. These infants (Fig. 3) resembled those in the previous group in their exaggerated response to external stimuli, and in their alert rather anxious facies. On the other hand they showed no evidence of neck retraction, and while in many instances there was a fullness, there was no taut distension of the fontanelle. There were instances of nystagmus and other abnormal ocular movements but these had none of the violent characteristics of the grossly severe clinical picture. Exaggeration of the tendon reflexes was constant and many cases showed transient

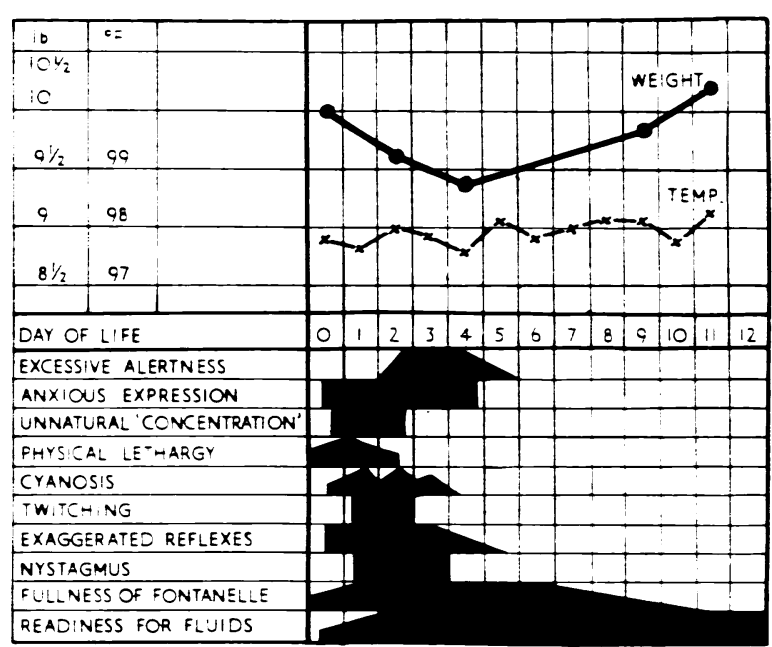

FIG. 3.-Diagram of a case showing severe clinical signs of intracranial irritation.

Instrumental rotation of head and instrumental extraction. Considerable bruising at birth. Right spastic hemiplegia confirmed at 5 years. (Appendix: Case No. 181.)

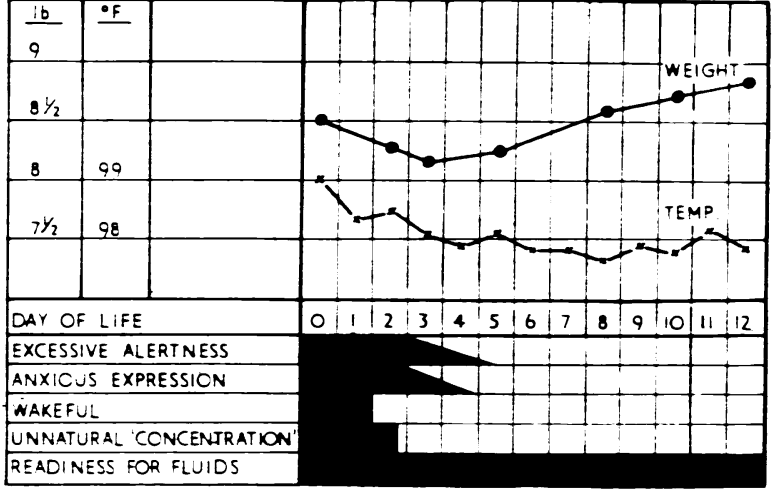

FIG. 4.-Diagram of a case showing pronounced but not severe clinical signs.

Spontaneous delivery: breech presentation. First attempts at speech at 3 years : gross mental disability at 5 years. (Appendix: Case No. 191.)

twitching of the face and extremities. Physical weakness was not at first a feature. There was, however, an element of physical lethargy which contrasted with the alert facial expression. The lethargy gradually gave place to a noticeable restlessness. At no time did these infants show any disinclination for fluids. Initially their colour was slightly cyanosed, but rapidly improved although in some cases there was a tendency for mild attacks of cyanosis to recur over a period of several days. Pulse and respiration, but not the temperature, sometimes showed slight departures from normal. There was little interference with weight progress.

Infants in this group numbered 104 of whom 27 were premature, 56 were born at term, and 21 were post-mature. Thirty-two infants were delivered spontaneously, 69 instrumentally, and three by Caesarean section. Instrumental delivery followed rotation of the head in 38 cases.

(C) Pronounced Clinical Signs. Diagnosis in the case of these infants (Fig. 4) depended on appreciation of the baby's unnatural alertness, precocious expression, apparent concentration on his surroundings, disinclination to sleep and slight 'jumpiness' when approached-all considered in relation to the history of birth. In no other respect did these infants give cause for concern. Their general physical condition was satisfying and improved progressively. There were no abnormal movements of face, limbs, or eyes. Temperature, pulse, and respiration were normal. Usually all clinical signs disappeared in the course of three to four days.

Of the 238 infants in this group, 91 were premature, 113 were born at term, and 34 were post-mature. Seventy infants were delivered 
spontaneously, 164 instrumentally, and four by Caesarean section. Rotation of the head was carried out before instrumental delivery in 42 cases.

(D) 'Minor' and Transitory Clinical Signs. These infants (Fig. 5) provided a striking clinical contrast to those already described. Their condition was invariably unsatisfactory at birth. In a way difficult to describe, fragility dominated the clinical picture. In much the same way the general condition gave cause for more concern than the local trauma. There was a pronounced and persistent disinclination to take fluids. A cry when

\begin{tabular}{|c|c|c|c|c|c|c|c|c|c|c|}
\hline \multirow{2}{*}{$\frac{16}{41 / 2}$} & \multirow[t]{2}{*}{ 觙 } & \multirow{2}{*}{+2} & \multicolumn{2}{|l|}{$\longrightarrow$} & & 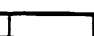 & \multicolumn{2}{|r|}{ 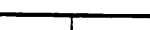 } & \\
\hline & & & & & & & & & & \\
\hline $31 / 2$ & 98 & & & & & & & & & \\
\hline 3 & 97 & & & & & & & & & \\
\hline \multicolumn{3}{|c|}{ DAY OF LIFE } & 0 & 5 & 10 & 15 & 20 & 25 & 30 & 35 \\
\hline \multicolumn{11}{|c|}{\begin{tabular}{|l|} 
FRAILTY \\
DISINCLINATION FOR FLUIDS \\
\end{tabular}} \\
\hline \multicolumn{11}{|c|}{ TWITCHING } \\
\hline \multicolumn{11}{|c|}{\begin{tabular}{|l|l} 
NYSTAGMOID MOVEMENTS & \\
\end{tabular}} \\
\hline \multirow{2}{*}{\multicolumn{11}{|c|}{$\begin{array}{l}\text { RECOGNIZABLE PHYSICAL IMPROVEMENT } \\
\text { WHINING CRY }\end{array}$}} \\
\hline & & & & & & & & & & \\
\hline
\end{tabular}

Fig. 5.-Diagram showing transitory or ' minor' clinical signs.

Spontaneous delivery: frail at birth. Spasticity of both arms and left leg and deficient development of left leg noted at age of 5 months. (Appendix: Case No. 63.)

heard was characteristically weak and whining. Flickering nystagmoid movements of the eyes took place but at irregular intervals so that detection of them at the time of any one examination was to some extent a matter of chance. The same was largely true concerning twitching movements of the extremities and to a lesser extent twitching of the face. No assistance was to be gained from examination of the fontanelle. The weight progress was characteristic. With remarkable consistence there was a slow gradual decline for some 10 to 14 days followed by a prolonged and anxious period during which little if any of the loss was recovered. Subsequent improvement of the weight was significantly slow and could be measured only over long periods. Of particular importance from the point of view of diagnosis was the absence of any of those characteristics of the facies which were so outstanding a feature in infants included in the other clinical groups.

The group includes 187 infants, of whom 63 were born prematurely, 122 were born at term, and two were post-mature. Delivery was spontaneous in 141 , instrumental in 40 , and by Caesarean section in 6.

(E) Delayeg Clinical Signs of Considerable SEVERITY. This was a small but clearly defined group (Fig. 6). The clinical picture was so characteristic that sisters and house physicians having seen only one case were quick to recognize the resemblance to it on the occurrence of the second. All 11 babies in this group were large, full term infants and delivery of nine was spontaneous. A remarkable feature of these nine deliveries was that they were all associated either with violent pains resulting in precipitate delivery, or with labours which had been prolonged despite persistently strong pains. The remaining two of the total 11 cases were delivered by Caesarean section after unsuccessful trial of labour.

Exhaustion rather than shock dominated the picture at birth. Excessive quiet and abnormal activity persisted. The eyes remained constantly open; the expression of the face was sullen and frowning; the body temperature was low, and the pulse and respiration were slow. Without exception, tendon reflexes were absent or difficult to elicit. There was no neck rigidity, no bulging of the fontanelle, and no cry. Fluids, when offered, were taken lazily. The clinical picture remained static for a period varying from 10 to 13 days except that characteristically the weight fell with pronounced rapidity. At the end of that period the eyes showed evidence of becoming progressively sunken and a phase of slow decline set in. An even more dramatic change followed. Abnormal inactivity gave way to intense and continuous restlessness. Previously unnaturally quiet, the infant began to cry in a piercing fashion. The sullen frowning facial expression was transformed overnight into one of unmistakable and intense fear. In the case of four infants this transformation was accompanied by a degree of frenzied activity which must be seen to be appreciated. Freed from the restraint of cot clothes these infants almost flung themselves from side to side in a way suggestive of agonizing pain and difficult to credit as being possible in babies of such tender age. There were no convulsions. Intensive sedative therapy was effective in controlling these developments. 


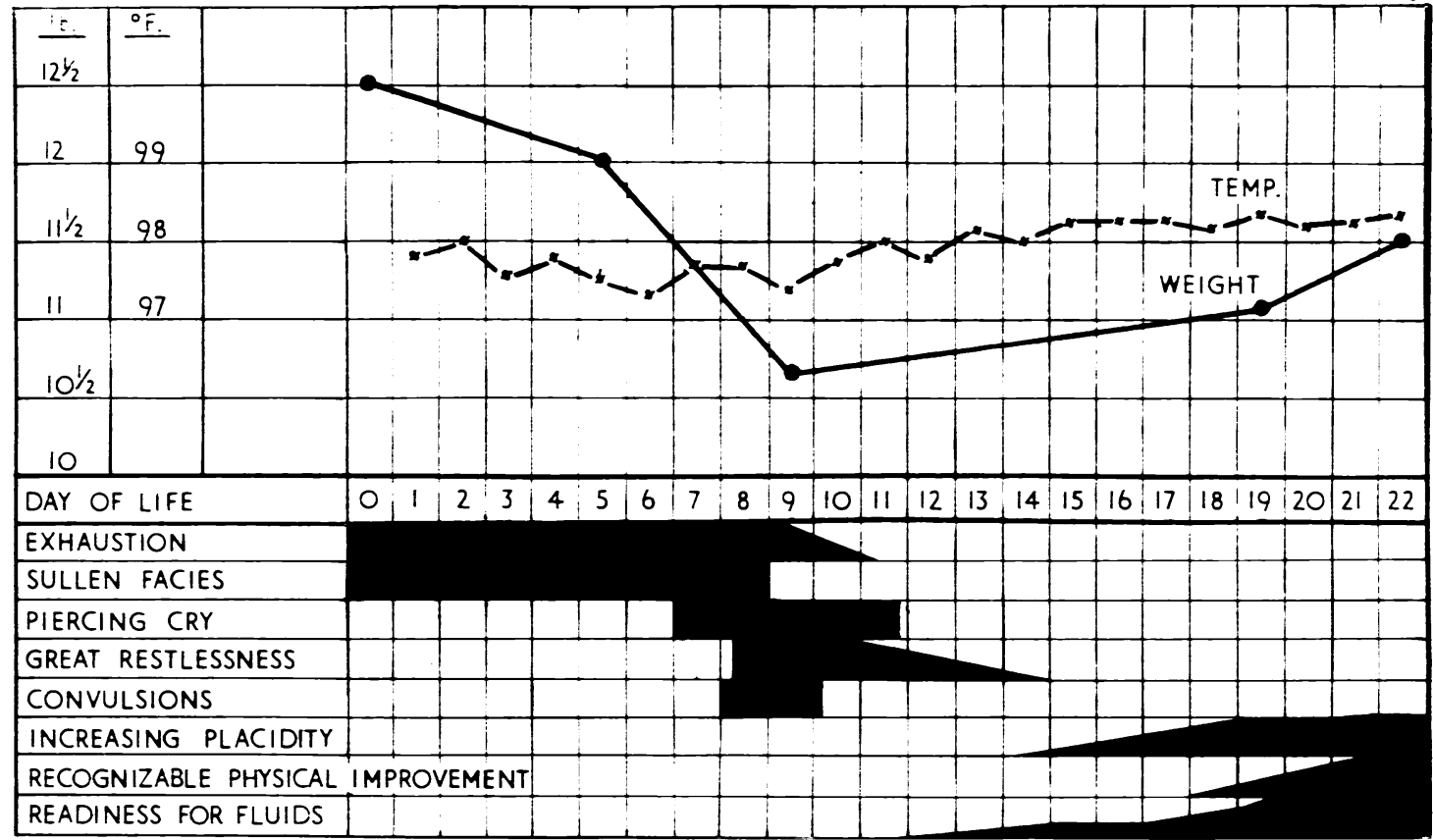

FIG. 6.-Diagram showing delayed clinical signs of considerable severity.

Spontaneous delivery: prolonged labour: foetal distress. Nystagmus, ataxia. and doubtful deafness at 2-3 years. (Appendix: Case No. 689.)

Infants and Children Included in the Follow-up Survey. All 593 infants included in Table 1 were seen and examined about the age of 6 months. Of these 593 infants, 306 were followed up to an age of not less than 5 years, 55 to the age of 3 years, and 111 to the age of 1 year. Several factors contributed to the failure to follow up for more than three years $40^{\circ}$ o of children included in the original series. In the great majority of cases, loss of contact resulted from families changing their place of residence, a factor which was appreciably aggravated during the war years. Thirty-six children are known to have died in the course of the survey. Reliable information was not obtained concerning the causes of death.

Residual Phenomena in Children Included in the Follow-up Survey. The presence of physical or mental disability, separately or coincidentally was confirmed in the case of 52 children, and a reliable history of convulsions in the absence of evidence of either physical or mental disability was obtained in four cases. Clinical details concerning the 56 children involved are summarized in the Appendix. Physical disability alone was present in 19 children. Physical and mental disability were both present in 18 children. The mental condition was doubtful in four other children with physical disability.
Mental disability was evident in nine children showing no signs of physical handicap and was suspected in one other child without physical disability.

Hemiplegia was the commonest form of physical handicap, and as in other paralyses was severe in some cases and slight in others. Instances were encountered of flaccid pareses which showed progressive or retrogressive. but gradual, changes in severity over limited periods of time. The series includes two cases of spastic diplegia which were not associated with microcephaly and which were considered to be the result of birth trauma and not evidence of errors in foetal development. All degrees of mental disability were encountered. Pronounced personality changes were an associated feature in a small number of cases.

The findings are summarized in Tables 2. 3, 4. and 5. From Table 5 it will be seen that while physical disabilities were first recognized after varying intervals of time following birth the great majority were suspected in the first year of life, but that instances occurred of physical handicap first evidencing itself between the ages of 1 and 6 years. In contrast mental disability was not seriously suspected in any child under the age of 9 months, and in most cases was first suspected around the 
TABLE 1

593 INfants WITH INTRacrantal IrRTtation following Deluvery

\begin{tabular}{|c|c|c|c|c|c|c|c|c|}
\hline \multirow{3}{*}{\multicolumn{3}{|c|}{ Nature of Delivery }} & \multicolumn{6}{|c|}{ Maturity } \\
\hline & & & \multicolumn{2}{|c|}{ Premature } & \multicolumn{2}{|c|}{ Full-term } & \multicolumn{2}{|c|}{ Post-Mature } \\
\hline & & & $\begin{array}{c}\text { First } \\
\text { Pregnancy }\end{array}$ & $\begin{array}{l}\text { Other than } \\
\text { First } \\
\text { Pregnancy }\end{array}$ & $\begin{array}{c}\text { First } \\
\text { Pregnancy }\end{array}$ & $\begin{array}{l}\text { Other than } \\
\text { First } \\
\text { Pregnancy }\end{array}$ & $\begin{array}{c}\text { First } \\
\text { Pregnancy }\end{array}$ & $\begin{array}{l}\text { Other than } \\
\text { First } \\
\text { Pregnancy }\end{array}$ \\
\hline \multicolumn{3}{|l|}{$\begin{array}{c}\text { Spontaneous } \\
\text { Vertex }\end{array}$} & 89 & 18 & 66 & 18 & 10 & 5 \\
\hline Breech & . & .. & 23 & 7 & 14 & 7 & & 4 \\
\hline \multicolumn{3}{|l|}{$\begin{array}{c}\text { Instrumental } \\
\text { Vertex }\end{array}$} & 31 & 13 & 89 & 26 & 17 & 2 \\
\hline \multicolumn{3}{|c|}{$\begin{array}{l}\text { Vertex preceded by } \\
\text { manual or instrumental } \\
\text { rotation of the head }\end{array}$} & & & 63 & 24 & 13 & 2 \\
\hline Breech & .. & . & 5 & 3 & 7 & 11 & 9 & 1 \\
\hline \multirow[t]{2}{*}{ Caesarean Section } & .. & . & & & 6 & 7 & 2 & 1 \\
\hline & & & \multicolumn{2}{|c|}{189} & \multicolumn{2}{|c|}{338} & \multicolumn{2}{|c|}{66} \\
\hline
\end{tabular}

TABLE 2

Children with Physical Disabilities

\begin{tabular}{|c|c|c|c|c|c|c|c|c|}
\hline \multirow{3}{*}{\multicolumn{3}{|c|}{ Disability }} & & \multicolumn{4}{|c|}{ Number of Cases with } & \multirow{3}{*}{$\begin{array}{c}\text { Total } \\
\text { Number }\end{array}$} \\
\hline & & & & \multirow{2}{*}{$\begin{array}{l}\text { No Associated } \\
\text { Mental Disability }\end{array}$} & \multicolumn{3}{|c|}{ Associated Mental Disability } & \\
\hline & & & & & Doubtful & Moderate & Severe & \\
\hline \multicolumn{3}{|c|}{$\mathbf{A}$} & & $\mathbf{B}$ & $\mathbf{C}$ & $\mathbf{D}$ & $\mathbf{E}$ & $\mathbf{F}$ \\
\hline Hemiplegia & . & .. & .. & 11 & 1 & 4 & 1 & 17 \\
\hline Monoplegia .. & . & .. & .. & 4 & 1 & 3 & & 8 \\
\hline \multicolumn{3}{|c|}{ Bilateral asymmetrical paralysis } & . & 3 & & 1 & 1 & 5 \\
\hline Spastic diplegia* & . & . & .. & & 1 & 1 & & 2 \\
\hline Hydrocephalus & .. & .. & .. & 1 & 1 & 1 & 1 & 4 \\
\hline \multicolumn{2}{|c|}{ Ataxia and/or athetosis } & .. & .. & & & 2 & 3 & 5 \\
\hline Totals ... & .. & . & .. & 19 & 4 & 12 & 6 & 41 \\
\hline
\end{tabular}

- Neither case showed evidence of microcephaly. 
TABLE 3

Children with Mental Disabiuty

\begin{tabular}{|c|c|c|c|c|c|c|c|c|}
\hline \multirow[b]{3}{*}{$\begin{array}{l}\text { Degree of Mental } \\
\text { Disability }\end{array}$} & \multirow{3}{*}{$\begin{array}{c}\text { No } \\
\text { Associated } \\
\text { Physical } \\
\text { Disability }\end{array}$} & \multicolumn{6}{|c|}{ Number of Cases with } & \multirow[b]{3}{*}{$\begin{array}{c}\text { Total } \\
\text { Numbe } \\
\text { of Case }\end{array}$} \\
\hline & & \multicolumn{6}{|c|}{ Associated Physical Disability } & \\
\hline & & $\begin{array}{l}\text { Hemi- } \\
\text { plegia }\end{array}$ & $\begin{array}{c}\text { Mono- } \\
\text { plegia }\end{array}$ & $\begin{array}{l}\text { Bilateral } \\
\text { Asym- } \\
\text { metrical } \\
\text { Paralysis }\end{array}$ & $\begin{array}{l}\text { Spastic } \\
\text { Diplegia }\end{array}$ & $\begin{array}{l}\text { Hydro- } \\
\text { cephalus }\end{array}$ & $\begin{array}{l}\text { Ataxia } \\
\text { and or } \\
\text { Athetosis }\end{array}$ & \\
\hline $\mathbf{A}$ & B & $\mathbf{C}$ & $\mathbf{D}$ & $\mathbf{E}$ & $\mathbf{F}$ & G & $\mathbf{H}$ & $\mathbf{I}$ \\
\hline $\begin{array}{l}\text { Severe emotional } \\
\text { instability } \ldots\end{array}$ & & & & & & & (1) & (1) \\
\hline $\begin{array}{c}\text { Mental Disability } \\
\text { Doubtful }\end{array}$ & 1 & 1 & 1 & & 1 & 1 & & 5 \\
\hline Moderate & 6 & 4 & 3 & 1 & 1 & 1 & 2 & 18 \\
\hline Severe & 3 & 1 & & 1 & & 1 & 3 & 9 \\
\hline Totals & 10 & 6 & 4 & 2 & 2 & 3 & 5 & 32 \\
\hline
\end{tabular}

age of 3 years. Convulsions first occurred in the majority of cases involved at some time during the first six months of life, but in some few cases their first appearance was delayed until about the second or third birthday.

TABLE 4

Children With Convulsions OCCURRING AFter the AgE Of THREE WeEkS

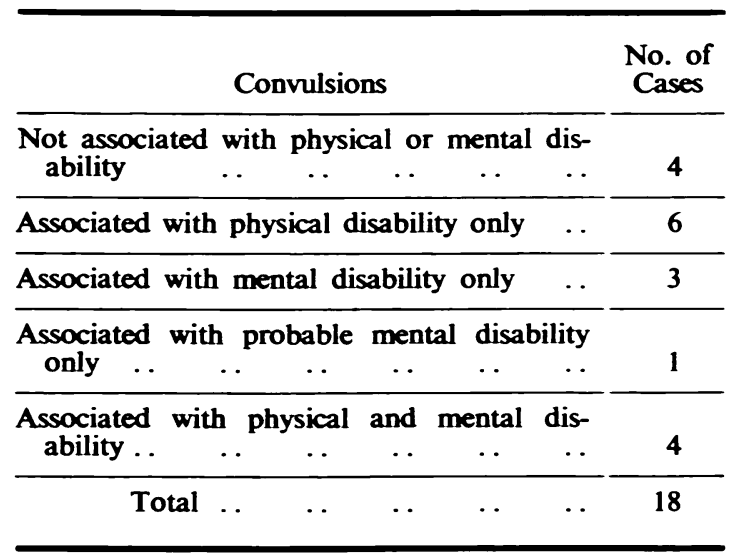

\section{Discuscion}

Limitations of the Investigation. It is important that limitations attached to the investigation should receive full recognition in any assessment of the results. The following are among these limitations:

(i) The collection of new clinical material was subject to interruption during the period 1938-1941, thus temporarily interfering with the continuity of the investigation.

(ii) The clinical material included in the investigation was drawn from a number of widely separated geographical areas in Scotland and England. The results, therefore, have no local, geographical, or regional significance.

(iii) Of cases included in the series under discussion, over $92 \%$ were born in maternity hospitals and maternity homes with the result that the findings of the inquiry inevitably reflect the influence of the high incidence of first and abnormal pregnancies characteristic of institutional midwifery.

(iv) Maternity hospitals or hospital departments and maternity homes in which children included in the investigation were born totalled 12. Obstetrical procedures and nursing methods varied from institution to institution. General deductions concerning aetiological factors are as a result not justifiable. On the other hand, the variations in obstetrical and nursing procedure in no way invalidate deductions which are based on a correlation of clinical findings with the obstetrical history and relate to an individual infant.

(v) The follow-up survey does not include a control series of children with an uneventful neonatal history.

Summarized it may be said that the investigation under consideration consists of a clinical study based upon material unavoidably obtained in a way which precludes any statistical analysis.

Diagnosis. The clinical observations on which a diagnosis of intracranial irritation was based have 
TABLE 5

Approximate Age of First Recogntion of Residual Phenomena or late Sequelae

No. of Children

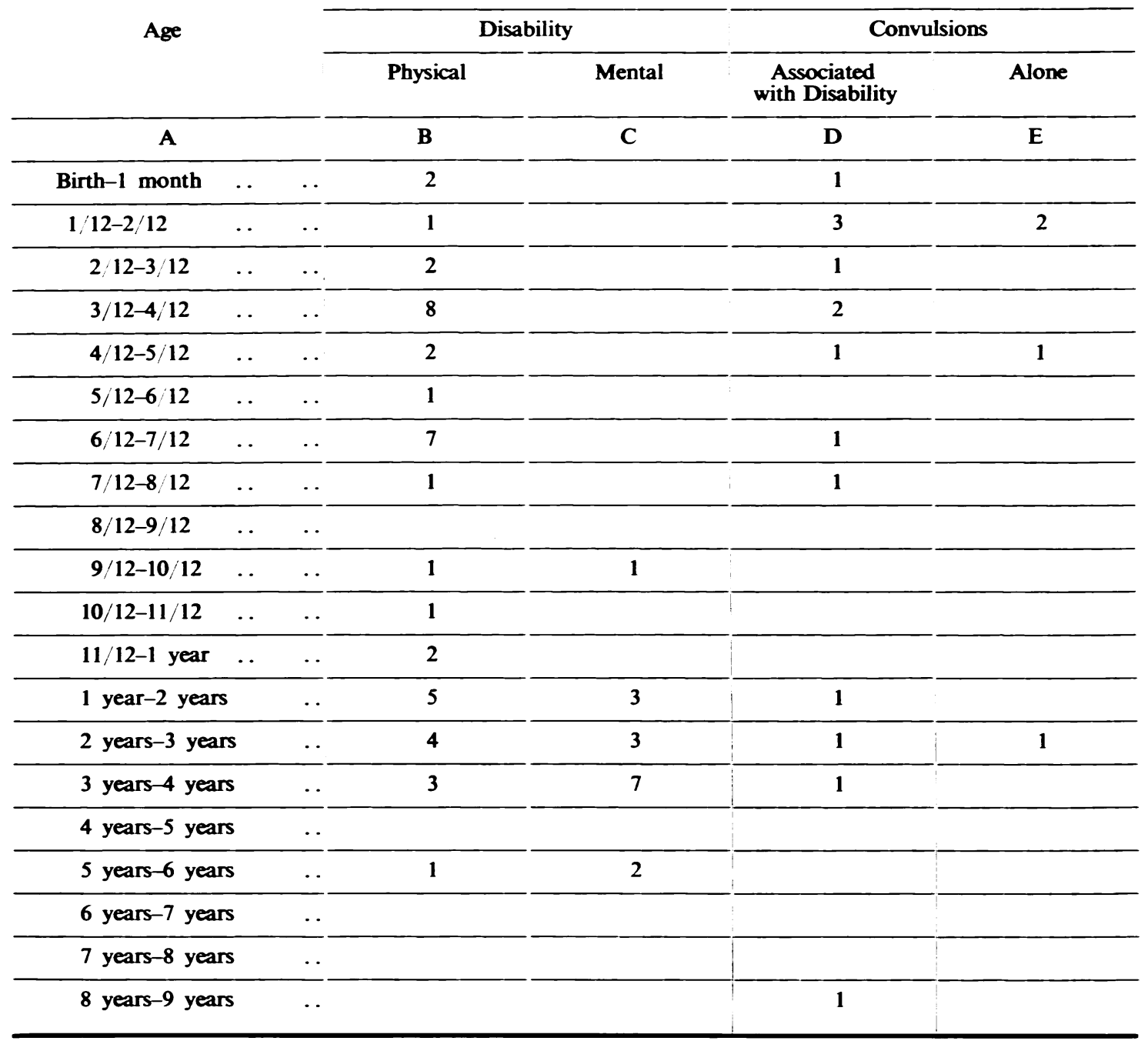

already been described. In an earlier publication (1938) the writer emphasized the importance of a physiognomical diagnosis which takes account of the obstetrical history, of the maturity of the child, and of the condition of the fontanelle. Subsequent studies (unpublished) concerned with the correlation of observations during life and post-mortem findings in fatal cases have confirmed these conclusions.

Clinical signs were of all degrees of severity. They were present within 48 or 72 hours of birth in the great majority of cases. Very exceptionally their appearance was delayed until the second week of life. Violent signs were rarely met with in premature infants, whose frail condition tended to exercise a 'damping' effect on outward evidences of intracranial irritation. Moderately pronounced evidences of intracranial irritation were not, however, confined to premature infants, but occurred in babies of all degrees of maturity and size.

The Underlying Pathology. The term 'intracranial irritation' has been used throughout in preference to cerebral haemorrhage as being more 
in keeping with the clinical purpose of this study, and because it embraces both cerebral and meningeal oedema which so often figure largely in necropsy findings on fatal cases.

It is possible to hazard a guess as to the pathological nature of the underlying intracranial condition in a proportion of those cases presenting severe signs and symptoms. To attempt to do so in all cases would have introduced a problematical element contrary to the interests of the investigation. Allowing this, there is one group of six cases which justifies special attention.

The group consists of the following cases in the Appendix, nos. 119, 203, 311, 481, 689, and 698 . These six children (of whom five were first children and one a second child), had in common that they suffered from severe mental disability and showed evidence of an ataxic gait and/or intention tremor and/or athetosis. Three of the six children had nystagmus. Delivery of five was spontaneous and of one by high forceps. Presentation in one of the spontaneous deliveries was a breech. Foetal distress was recorded in two instances. Labour was prolonged in four cases, and there were violent pains in a fifth. All six children were large at birth ranging from $8 \mathrm{lb}$. to $12 \frac{1}{2} \mathrm{lb}$., and showed signs of extreme exhaustion over a period of several days. In all six cases there was delay in the appearance of signs pointing to cerebral irritation, and after their appearance these signs assumed a violent form. The day after birth on which signs of intracranial irritation appeared varied from the fifth to the thirteenth. In many respects the obstetrical histories and the clinical course in the neonatal period of these children resemble those previously described in connexion with fatal cases showing signs of gross intracerebral haemorrhage at necropsy (Craig, 1938). It appears possible, at least, that some if not all of the six cases in the present series survived intracerebral birth haemorrhage, and that the haemorrhage, as judged by the clinical manifestations, had involved the cerebellum and/or mid-brain.

A further point of significance is that of cases included in the present series, not one presented clinical features simulating those described in connexion with intraventricular haemorrhage (Craig, 1938).

Prognosis. Immediate prognosis is especially grave where in the hours immediately following delivery the infant remains in a state of complete collapse and persistently pale. Breathing is gasping, shallow, and irregular. The pulse is almost imperceptible. The state of the fontanelle, the reactions to external stimuli, and the temperature afford no information of value. In the presence of such a clinical picture, more especially when associated with periods of deep cyanosis, death is likely to occur within 48 hours of birth.

The occurrence of violent signs and symptoms of necessity makes for increased gravity of the prognosis but is not incompatible with survival. A small number of the infants in the present series presented clinical pictures which were among the stormiest I had seen at any time. The severity of clinical manifestations must be judged in conjunction with their frequency, persistence, and duration. Pronounced convulsive as distinct from mild twitching movements in a premature infant more often than not presage death. Violent irritability, a bulging fontanelle, intense restlessness and convulsions when they appear for the first time in the second week of life point to the recurrence of haemorrhage or of an unusual pathology, and are to be considered of grave prognostic significance. Vomiting which begins on the first day or two of life and persists in the absence of a primary alimentary or urinary cause is of serious significance during such time as it lasts. Head retraction of any degree, more especially if associated with recognizable neck rigidity is strongly suggestive of massive subtentorial bleeding with its attendant risks of pressure symptoms. A full, as distinct from a taut fontanelle is, of itself, not of great significance in prognosis. Its significance is dependent upon the character and severity of other detectable signs. Importance attaches to an infant's readiness to take fluids. In the small infant with minor or transitory signs of cerebral irritation readiness to take fluids is frequently the first evidence of improvement. Among infants showing the grosser signs of intracranial irritation, it is characteristic of those who eventually survive that they show a consistent readiness to take fluids from the early hours of life. In contrast, disinclination for fluids is a frequent finding in those newly born infants who ultimately die in the first week of life as a result of cerebral injury.

Even in those cases in which presenting signs are moderate or only slight, it is a wise rule to postpone giving an unreservedly confident immediate prognosis until the end of the first week. Relapses are liable to occur on the third day, but more especially on the fifth or sixth day. On the other hand it is a common experience, particularly where the patient is a full-term infant, to find improvement which previously has been vague, assuming definite form on or around the seventh day of life.

As a case of intermediate severity responds to treatment, twitching and convulsive movements disappear; responses to external stimuli lose some of their violence; movements of the eyes become 
less and less agitated in character; in succession the frown disappears from the brow, the apprehension from the expression, and the concentration from the gaze; and eventually the eyes from being continuously open remain closed. Changes in the fontanelle tend to lag behind the disappearance of other signs. Depending upon its condition shortly after the delivery, the fontanelle becomes less tense and bulging so that it conveys an impression of 'boggy fullness' to the examining finger. Eventually, although it may not be until the third or fourth week of life, the fontanelle conforms with the usual normal findings.

As improvement in the general condition becomes more evident, various minor changes occur which collectively justify confidence in prognosis. The infant sleeps unbrokenly between feeds. His cry when hungry assumes a normal character where before it was either petulant or infrequent. Movements of the tongue which were restless and lacking apparent purpose become rhythmic. To hear the infant 'smacking his lips' as he fixes on the breast or teat with obvious satisfaction is a reliably reassuring sign. So also is the way in which as their condition improves these infants can be seen lazily stretching their limbs. The picture is one of contentment and replete satisfaction.

Pulse and temperature observations have a prognostic value in a limited number of cases only. An appreciably raised temperature is not often encountered.

A detailed study of the obstetrical and clinical histories of the 56 children who developed residual phenomena or late sequelae affords no clue as to ultimate prognosis. Disability of one kind or another developed alike in premature, full-term, and post-mature infants surviving signs of neonatal intracranial irritation, and the preponderance of children with birth weights of between $5 \frac{1}{2}$ and $10 \frac{1}{2} \mathrm{lb}$. (Table 5) was no more than was accounted for by the preponderance of such children in the complete series (Table 1).

Physical debility, alone or in association with mental disability was recorded in infants born before, at and after term. No instance was encountered of mental disability without associated physical handicap among infants born prematurely. A feature of the obstetric histories of infants developing sequelae was that whereas in 12 premature births there was only one instance of rapid delivery and one case of foetal distress, in the births of 44 infants each weighing over $5 \frac{1}{2} \mathrm{lb}$., foetal distress was recorded in seven, prolonged labour in 11 , violent pains in two, and precipitate delivery in one. There was no evidence of asphyxia at birth in any of the
12 premature infants. Of the other 44 infants, nine were recorded as being asphyxiated at birth (Table 6).

Correlation of the clinical picture during the neonatal period with the clinical findings noted in the course of the follow-up survey does not suggest that the severity of the early post-natal signs bears any direct relation to the likelihood of residual phenomena developing, or to the nature of the phenomena in those cases in which they do develop (Table 7). Of the premature infants who ultimately developed physical or physical and mental disability, not one had presented violent or gross signs during the early days or weeks of life (Table 7 and Appendix). On the other hand, among infants weighing more than $5 \frac{1}{2} \mathrm{lb}$. at birth, there were many instances of violent neonatal clinical courses being followed by uneventful physical and mental development, and a number of examples of severe disability (physical and/or mental) occurring as sequelae despite the fact that signs of intracranial irritation following birth had been minimal (e.g., Appendix, Case Nos. 191, 396, 580, 611). The one exception to this generalization is that prognosis with regard to physical and mental development is especially poor in cases of the type which suggests survival from intracerebral haemorrhage. One baby in this last group was noted as being markedly obese when re-examined at the age of 5 years (Appendix: Case No. 481).

Symptoms may be measured by their severity. They may be measured also by their duration

\begin{tabular}{|c|c|c|c|c|}
\hline \multirow{2}{*}{$\begin{array}{c}\text { CLINICAL } \\
\text { GROUP }\end{array}$} & \multicolumn{3}{|c|}{$\begin{array}{c}\text { DURATION OF NEONATAL } \\
\text { SYMPTOMS }\end{array}$} & $\begin{array}{c}\text { NUMBER } \\
\text { (WEESS) } \\
\text { OF }\end{array}$ \\
\cline { 2 - 4 } & $\begin{array}{c}\text { LESS THAN } \\
\text { ONE }\end{array}$ & $\begin{array}{c}\text { BETWEEN } \\
\text { ONE ONd TWO }\end{array}$ & $\begin{array}{c}\text { MORE THAN } \\
\text { TWO }\end{array}$ & CHILDREN \\
\hline $\begin{array}{c}56 \\
\text { INFANTS } \\
\text { SUBSEQUENTLY } \\
\text { DEVELOPING } \\
\text { SEQUELAE }\end{array}$ & & & & 20 \\
\hline \hline $\begin{array}{c}\text { 2IO } \\
\text { INFANTS } \\
\text { NONE OF } \\
\text { WHOM SHOWED } \\
\text { EVIDENCE OF } \\
\text { SEOUELAE AT } \\
\text { AGE S YEARS }\end{array}$ & & & & 10 \\
\hline
\end{tabular}

Fig. 7.-Diagram showing duration of neonatal symptoms.

* Limited to infants whose records were sufficiently detailed for inclusion in this figure.

regardless of their severity. Fig. 7 shows the duration of neonatal symptoms of intracranial irritation in infants of the present series according as they did or did not subsequently develop residual 
TABLE 6

analysis of Data of 56 Children showing Residual Phenomena or late Sequelae in relation to Natal Factors

Number of Children

\begin{tabular}{|c|c|c|c|c|c|c|c|c|c|c|c|c|c|c|c|c|c|}
\hline \multirow{3}{*}{$\begin{array}{c}\text { Birth } \\
\text { Weight } \\
\text { (lb.) }\end{array}$} & \multicolumn{2}{|c|}{$\begin{array}{l}\text { Place in } \\
\text { Family }\end{array}$} & \multicolumn{4}{|c|}{ Labour } & \multicolumn{5}{|c|}{ Delivery } & \multirow[b]{3}{*}{$\begin{array}{l}\text { Caes. } \\
\text { Sect. }\end{array}$} & \multirow{3}{*}{$\begin{array}{c}\text { Asphyxia } \\
\text { at } \\
\text { Birth }\end{array}$} & \multirow{2}{*}{\multicolumn{4}{|c|}{$\begin{array}{c}\begin{array}{c}\text { Late Sequelae } \\
\text { and/or Residual } \\
\text { Phenomena }\end{array} \\
\text { Disability }\end{array}$}} \\
\hline & \multirow[b]{2}{*}{ 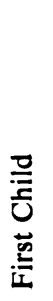 } & \multirow[b]{2}{*}{ 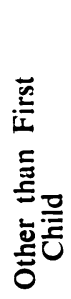 } & \multirow[b]{2}{*}{ 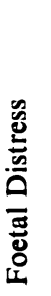 } & \multirow[b]{2}{*}{ 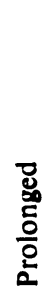 } & \multirow[b]{2}{*}{ 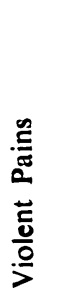 } & \multirow[b]{2}{*}{$\frac{\bar{z}}{\bar{a}}$} & \multicolumn{2}{|c|}{ Spontaneous } & \multicolumn{3}{|c|}{ Instrumental } & & & & & & \\
\hline & & & & & & & 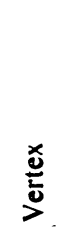 & 密 & 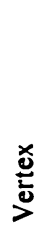 & 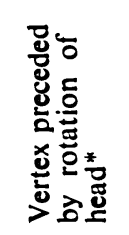 & 总 & & & $\frac{\overline{\vec{d}}}{\frac{\pi}{2}}$ & 吾 & 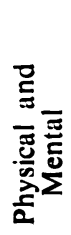 & 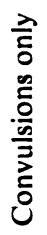 \\
\hline $\mathbf{A}$ & B & C & D & $\mathbf{E}$ & $\mathbf{F}$ & G & $\mathbf{H}$ & I & $\mathbf{J}$ & $\mathbf{K}$ & L & $\mathbf{M}$ & $\mathbf{N}$ & $\mathbf{O}$ & $\mathbf{P}$ & $\mathbf{Q}$ & $\mathbf{R}$ \\
\hline $\begin{array}{l}5 \frac{1}{2} \text { and } \\
\text { under } \ldots\end{array}$ & 5 & $7 \dagger$ & 1 & & & 1 & 7 & 3 & 2 & & & & & 8 & & 3 & 1 \\
\hline $\begin{array}{l}10 \frac{1}{2} \text { and } \\
\text { over } 5 \frac{1}{2}\end{array}$ & 28 & 12 & 7 & 10 & 2 & 1 & 16 & 2 & 12 & 8 & 1 & $1+$ & 6 & 15 & 7 & 15 & 3 \\
\hline Over $10 \frac{1}{2}$ & 2 & 2 & & 1 & & & 2 & & 1 & 1 & & & 3 & 1 & 1 & & \\
\hline
\end{tabular}

- Manual or instrumental rotation.

$\dagger$ One may have been first child.

After failed forceps.

TABLE 7

Correlation of Neonatal Cuinical Picture and Nature of Residual Phenomena in 56 Childen

\begin{tabular}{|c|c|c|c|c|c|c|c|c|c|}
\hline \multirow{4}{*}{$\begin{array}{c}\text { Birth } \\
\text { Weight } \\
\text { (lb.) }\end{array}$} & & \multicolumn{8}{|c|}{ Number of Children } \\
\hline & & \multicolumn{4}{|c|}{ Neonatal Clinical Picture: Symptoms } & \multicolumn{4}{|c|}{ Sequelae and Clinical Phenomena } \\
\hline & \multirow[b]{2}{*}{$\begin{array}{l}\text { Gross } \\
\text { Violent }\end{array}$} & \multirow[b]{2}{*}{$\begin{array}{c}\text { Pro- } \\
\text { nounced }\end{array}$} & \multirow[b]{2}{*}{ Moderate } & \multirow[b]{2}{*}{$\begin{array}{l}\text { Mild or } \\
\text { Transitory }\end{array}$} & \multirow[b]{2}{*}{ Delayed } & \multicolumn{3}{|c|}{ Disability } & \multirow{2}{*}{$\begin{array}{c}\text { Convul } \\
\text { sions } \\
\text { only }\end{array}$} \\
\hline & & & & & & Physical & Mental & $\begin{array}{c}\text { Physical } \\
\text { and Mental }\end{array}$ & \\
\hline $\mathbf{A}$ & $\mathbf{B}$ & $\mathbf{C}$ & $\mathbf{D}$ & $\mathbf{E}$ & $\mathbf{F}$ & G & $\mathbf{H}$ & I & $\mathbf{J}$ \\
\hline $\begin{array}{l}5 \frac{1}{2} \text { and } \\
\text { under }\end{array}$ & & & 3 & 9 & & 8 & & 3 & 1 \\
\hline $\begin{array}{l}10 \text { and } \\
\text { over } 5 \frac{1}{2}\end{array}$ & 10 & 8 & 15 & 3 & 4 & 15 & 7 & 15 & 3 \\
\hline Over $10 \frac{1}{2}$ & 1 & 2 & & 1 & & 1 & 1 & 2 & \\
\hline
\end{tabular}


phenomena. The number of children showing permanent effects is too small to allow of firm conclusions. Nevertheless the figures in the diagram do suggest, at least, that a persistence of neonatal symptoms of intracranial irritation may be more characteristic of the histories of children who develop sequelae than those of children who survive intracranial irritation without subsequent disability. The possibility merits careful investigation in view of its obvious bearing on treatment.

A point of some importance in relation to prognosis is the delay which may take place in the first appearance of residual phenomena (Table 5). Study of the 56 children in whom such phenomena developed affords no clue as to which cases are liable to develop late sequelae, or as to which cases known to have some form of disability are likely to be further complicated by disability of another kind or by convulsions.

Treatment in the Neonatal Period. The keystones to treatment are prevention, anticipation, and simplicity. Prevention is primarily an obstetrical responsibility. Anticipation is the concern of both obstetrician and paediatrician. Responsibility for instituting simple therapeutic measures and for reducing disturbance to a minimum rests with the paediatrician and the midwife or maternity nurse.

From the paediatric point of view, anticipation should begin with appreciation derived from a study of the obstetrical history of the possibility, at least, of intracranial trauma, and with recognition at the earliest possible moment of signs at all suggestive of intracranial irritation. Even a tentative diagnosis calls for immediate transfer of the infant to a room where he can be assured of complete quiet. For the necessary degree of quiet there must be no banging or constant opening and shutting of doors, and no unnecessary bustling to and fro of nursing staff. Visitors must be excluded. Draughts must be eliminated. The baby must be shielded from direct light whether natural or artificial. Body temperature must be maintained. The nurses in attendance should be selected for their experience in handling the ailing newly born child, and because of their proved ability to feed and attend to the toilet of infants with the minimum of disturbance.

Lumbar puncture is contraindicated even where the diagnosis remains in doubt. The operation is not a difficult one, but the extent to which the infant may be disturbed is too dependent upon the skill in handling by physician and nurse. Symptoms can readily be aggravated by inexpert handling and while immediate prognosis may not be materially affected, too little is known of the effects on ultimate prognosis to warrant lumbar puncture being undertaken other than in exceptional circumstances.
Nor has lumbar puncture a place in therapy. I have seen several cases in which lumbar puncture has precipitated a change for the worse in the general condition, but have not encountered any case in which there has been completely convincing proof of clinical improvement following lumbar puncture.

The position of the child is important. If there is a tendency for secretion to collect in the air passages the infant should be kept flat. Otherwise the head of the cot should be raised, and the child's head further elevated by propping him up slightly on firm pillows. Oxygen should be administered to all severe and moderately severe cases, to all infants who are premature, and to any case showing evidence of cyanosis whether transitory or persistent, and whether severe or slight. An oxygen chamber is always desirable. The value of a face mask is open to question and may contribute to restlessness, and the use of a nasal catheter is inadvisable on account of the risks of trauma to the nasal mucosa.

Medicinal therapy is of first importance. In my experience, there is rarely, if ever, occasion for use of any preparation other than chloral hydrate. The advantages of the drug are that it can be employed in relatively large doses at short intervals, and that its influence can be easily and rapidly adjusted to meet changing requirements by alteration of the dosage or the interval between doses or both. Failure of chloral hydrate to prove effective is almost invariably, if not always, due to inadequate dosage. In cases of extreme severity, one grain can be given half-hourly until violent symptoms are controlled. Subsequent dosage should be determined in the light of the persistence and severity of signs, of the degree of somnolence if present, and of the infant's readiness or otherwise to take fluids. Chloral hydrate does not give rise to gastric irritation in the newborn. It should never be withdrawn suddenly. Dosage should be reduced very gradually, reduction lagging behind successive evidences of improvement in the clinical condition. The drug should continue to be administered in half grain doses three or four times daily for several days after the complete disappearance of all symptoms.

An infant with signs, no matter how slight, suggestive of intracranial irritation, should not be lifted from his cot. Oesophageal feeding may be necessary in the case of small infants, but in general babies with intracranial irritation take fluids satisfactorily from a spoon if feeding is in the hands of an experienced nurse. There is no call for restriction of fluids or for any special modification of feeds on account of the infant's intracranial condition. It goes without saying that breast milk should be given wherever possible. The decision 
as to when a child who has been under observation or treatment for intracranial irritation should be put to the breast must rest with the paediatrician who should be present on the first occasion. Where symptoms of intracranial irritation have been slight, two days should be allowed to elapse between their disappearance and the beginning of feeding at the breast. In severe cases a much longer interval must be insisted upon, account being taken of the child's general condition.

I have not been convinced of the claims made for rectal hypertonic salines. Injections of this sort are by no means always retained and they are liable to cause unwarranted disturbance of the patient. The same can be said of vitamin $K$ preparations administered hypodermically. Clinical experience has not suggested that vitamin $K$ given after delivery influences the course of intracranial haemorrhage resulting from trauma, and the practice has been adopted of limiting its use to premature infants, in whom there is a greater likelihood of there being an associated hypoprothrombinaemia. Penicillin should be given orally when there is any suggestion of excessive secretion in the respiratory passages, when there is reason to suspect the presence of extensive atelectasis, or when there is a history of foetal distress.

A further point which requires emphasis is the frequency with which the prospects of an infant who has been born at home and who shows signs of intracranial irritation are prejudiced by precipitate and sometimes panic-like removal to hospital. Transfer under these circumstances should not be lightly undertaken, no matter how unsatisfactory the home conditions. Every effort should be made to secure the services of a district nurse or maternity nurse if one is not already in attendance, and intensive sedative therapy should be given trial, it may be over a period of two or three days before the infant is subjected to the risks entailed in removal. Premature transfer and ill-considered handling in the course of transfer undoubtedly contribute to avoidable deaths in infants with cerebral birth trauma.

Treatment is not complete which does not have regard to the emotional distress undergone by the parents. Mere mention of intracranial injury or suspected intracranial injury inevitably gives rise to understandable fears in the minds of the parents of a newly born infant. Their cooperation and confidence can best be won by a simple, sympathetic but strictly honest explanation of the probable course of events.

Prognosis is more likely to be reliable if it attaches as much importance to the obstetrical history as to the clinical symptoms presented by the child. The fact that a delivery has been instrumental is of less importance than the related circumstances of the delivery. A history of foetal distress or of severe asphyxia, whether the infant be premature or mature, is of greater significance than the fact that instruments were applied. Rotation of the head, whether manually or instrumentally, before forceps extraction tends to favour the occurrence of intracranial irritation. So also do prolonged labour, violent pains, and precipitate delivery-irrespective of the size of the infant.

Asked as to the prospects of immediate survival a guarded prognosis is called for until the end of the first week, but greater encouragement can be given with survival of each day after the fourth or fifth. Concerning ultimate prognosis, and subject to there not being already presumptive evidence of permanent disability, the clinician is entitled to emphasize the relative rarity with which sequelae occur in children who survive the neonatal period. He is under an obligation to reassure the mother on the grounds that severe symptoms at birth bear no constant relation to the likelihood of subsequent disability.

\section{Summary}

Clinical observations made over a period of 17 years in the course of a follow-up survey of 593 children diagnosed as having survived symptoms of intracranial irritation following birth are summarized. The investigation is a continuation of earlier published clinicopathological studies of intracranial haemorrhage in the newborn.

The histories and clinical findings of all children were carefully considered in relation to the possible operation of any familial, hereditary, or developmental factor. Children in connexion with whom any such factor was established or suspected were excluded from the series.

Children included in the series were examined personally within two days of birth, on several occasions during the neonatal period, and subsequently at varying intervals over a period ranging from one to five years.

Of the 593 children included in the series, 472 were followed up to the age of 1 year, 361 to the age of 3 years, and 306 to an age of not less than 5 years.

Neonatal symptoms of intracranial irritation are grouped according as they were violent (53 cases), severe (104 cases), pronounced (238 cases), mild or transitory (187 cases), or delayed (11 cases).

The presence of physical or mental disability, separately or in association was confirmed in the 
case of 52 children in the course of the follow-up survey. A reliable history of convulsions was obtained in the case of four other children without other handicap.

Physical disability was found alone in 19 children, and in association with severe mental disability in six, with moderate mental disability in 12 , and with doubtful mental disability in four children. Hemiplegia was the most common physical handicap (Table 2).

Mental disability without associated physical handicap was present in nine children. Of these, mental handicap was of severe degree in three and of moderate degree in six (Table 3).

Physical handicap in the case of the 41 children in whom it was present was detected under the age of 6 months in 16, between the age of 6 months and 1 year in 12, and over the age of 1 year in 13 . Of the 27 children in whom it was confirmed, mental disability was first suspected under the age of 12 months in one, between the ages of 1 year and 4 years in 13, and after the age of 5 years in two. Information on this point concerning 11 children in the group was unreliable.

Convulsions occurring after the first three weeks of life were a feature of 18 cases. They were associated with the presence of physical and/or mental disability in 14 cases. The time of their first occurrence varied. In 13 infants epileptiform attacks began within the first seven months of life; in four children between the ages of 1 and 4 years; and in one child after the age of 8 years.

It is emphasized that the investigation consists of a clinical study based upon clinical material unavoidably selected in such a way as to preclude any statistical analysis.

The importance of physiognomical diagnosis and of study of the behaviour pattern of the infant in arriving at a diagnosis of intracranial irritation in the newborn is emphasized. The clinical picture as it is found in the premature infant is contrasted with that encountered in the child born at term or after term. It is suggested that infants in whom symptoms of severe cerebral irritation arise from gross intracerebral haemorrhage present a characteristic clinical picture.

Immediate prognosis is discussed. It is considered that severe asphyxia and/or early violent signs while adding to the gravity of immediate prognosis are not incompatible with survival. The possibility of relapses occurring towards the end of the first week of life is stressed, and the especial dangers of violent signs delayed in their first appearance until the second week of life are emphasized. Importance is attached to study of the facies and behaviour pattern of the infant as of greater aid in determining prognosis than observations concerning changes in the state of the fontanelle and the character of the cry. Special value attaches to readiness to take fluids as justifying a certain measure of sober optimism.

Ultimate prognosis is considered in relation to the nature and severity of symptoms presenting in the early days of life. Symptoms of intracranial irritation in the neonatal period are considered to offer no reliable indication as to the likelihood of permanent sequelae developing, or as to the nature or time of development of residua should they subsequently appear. Infants in whom severe intracerebral haemorrhage is suspected constitute a possible exception.

It is suggested that the fact that a delivery has been instrumental is of less importance than related circumstances of the delivery, and that irrespective of the size or maturity of the child, and of the precise method of delivery, significance attaches to a history of foetal distress, severe asphyxia, prolonged labour, violent pains or precipitate delivery where a newborn infant shows any signs even slightly suggestive of intracranial irritation.

Simplicity in treatment is urged. Expert nursing care is essential. Handling should be reduced to a minimum. Absolute quiet and protection from external stimuli are important. Body temperature and adequate fluid intake must be maintained. Position is important. Lumbar puncture is contraindicated. Chloral hydrate is the drug of choice, given early, in large doses and frequently.

The view is held that the standards of nursing and medical care and the methods of treatment employed certainly have a direct bearing on immediate prognosis, and may have a bearing on ultimate prognosis by limiting the time during which symptoms of intracranial irritation persist.

Importance is attached to responsibility for the nursing care of newly-born infants with signs of intracranial irritation being given to nurses with special experience and training in the nursing of ailing newly-born and premature infants.

Precipitate transfer to hospital of a newborn infant born at home and showing signs of intracranial irritation is condemned as contributing to avoidable deaths. Greater use of facilities for domiciliary nursing care and careful selection of time for transfer to hospital (if eventually necessary) are advocated.

It is the rare exception and not the rule for an infant who survives signs of post-natal intracranial irritation and in whom there are no signs of residual disability during the neonatal period, to develop permanent sequelae. 
This investigation has only been made possible by the unstinted help received from colleagues in different parts of the country. To name a few would be to show lack of appreciation of the many. I can only express my deep indebtedness to the obstetricians, family doctors, medical officers of health, maternity and child welfare medical officers, midwives, health visitors and district nurses who constitute ' the many.'

\section{REFERENCES}

Anderson, N. A. (1945). In Mitchell-Nelson: 'Textbook of Pediatrics,' ed. Nelson, W. E. 4th ed. Philadelphia.

Benda, C. E. (1945). Medicine, Baltimore, 24, 71.

Capon, N. B. (1922). J. Obstet. Gynaec. Brit. Emp., $29,572$.

Clein, N. W. (1929). Amer. J. Dis. Child., 37, 750.

Craig, W. S. (1935). Edinb. med. J., 42, 599. (1938). Archives of Disease in Childhood, 13, 89.

Ehrenfest, H. (1922). 'Birth Injuries of the Child.' New York.
Fleming, G. B. (1931). Brit. med. J., 2, 481.

-, and Morton, E. D. (1930). Archives of Disease in Childhood, 5, 361.

Ford, F. R. (1926). Medicine, Baltimore, 5, 121. (1944). 'Diseases of the Nervous System in Infancy, Childhood and Adolescence.' Illinois.

Huenekens, E. J. (1923). J. Amer. med. Ass., 81, 624.

McGovern, J., and Yannet, H. (1947). Amer. J. Dis. Child., 74, 121.

Munro, D. (1928). Surg. Gynec. Obstet., 47, 622. (1930). New Engl. J. Med., 203, 502.

Roberts, M. H. (1939). J. Amer. med. Ass., 113, 280.

Rydberg, E. (1932). Acta. path. microbiol. scand. Suppl. 10.

Sharpe, W., and Maclaire, A. S. (1924). Surg. Gynec. Obstet., 38, 200.

Smith, L. H. (1934). Amer. J. Obstet. Gynec., 28, 89.

Tyson, R. M., and Crawford, W. H. (1931). Ibid., 21, 694 


\section{APPENDIX}

Details relating to Children showing Residual Phenomena or Late Sequelae

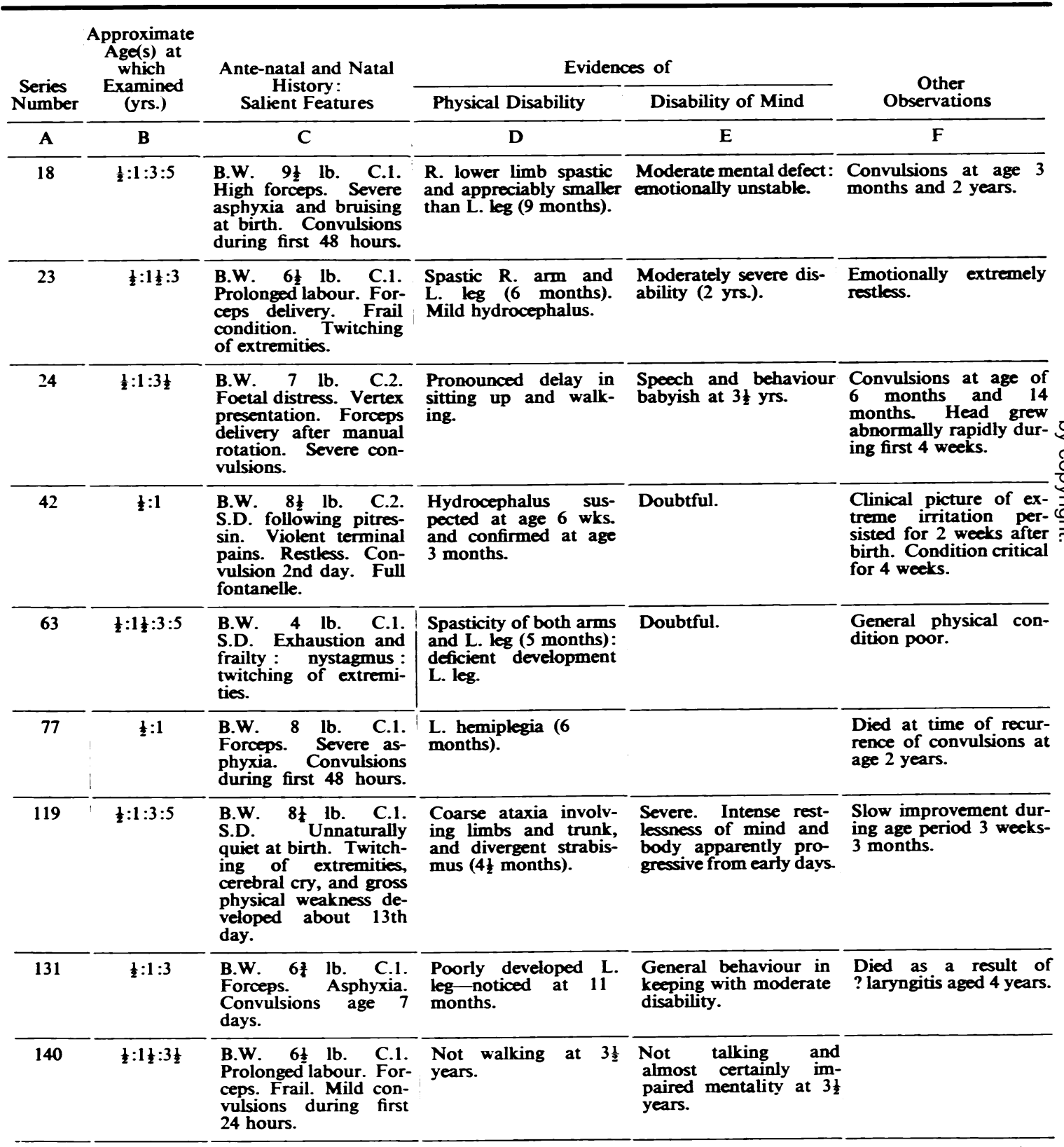

C. $1=$ First child, $C .2=$ Second child, etc.: $\quad$ B.W. $=$ Birth weight. 


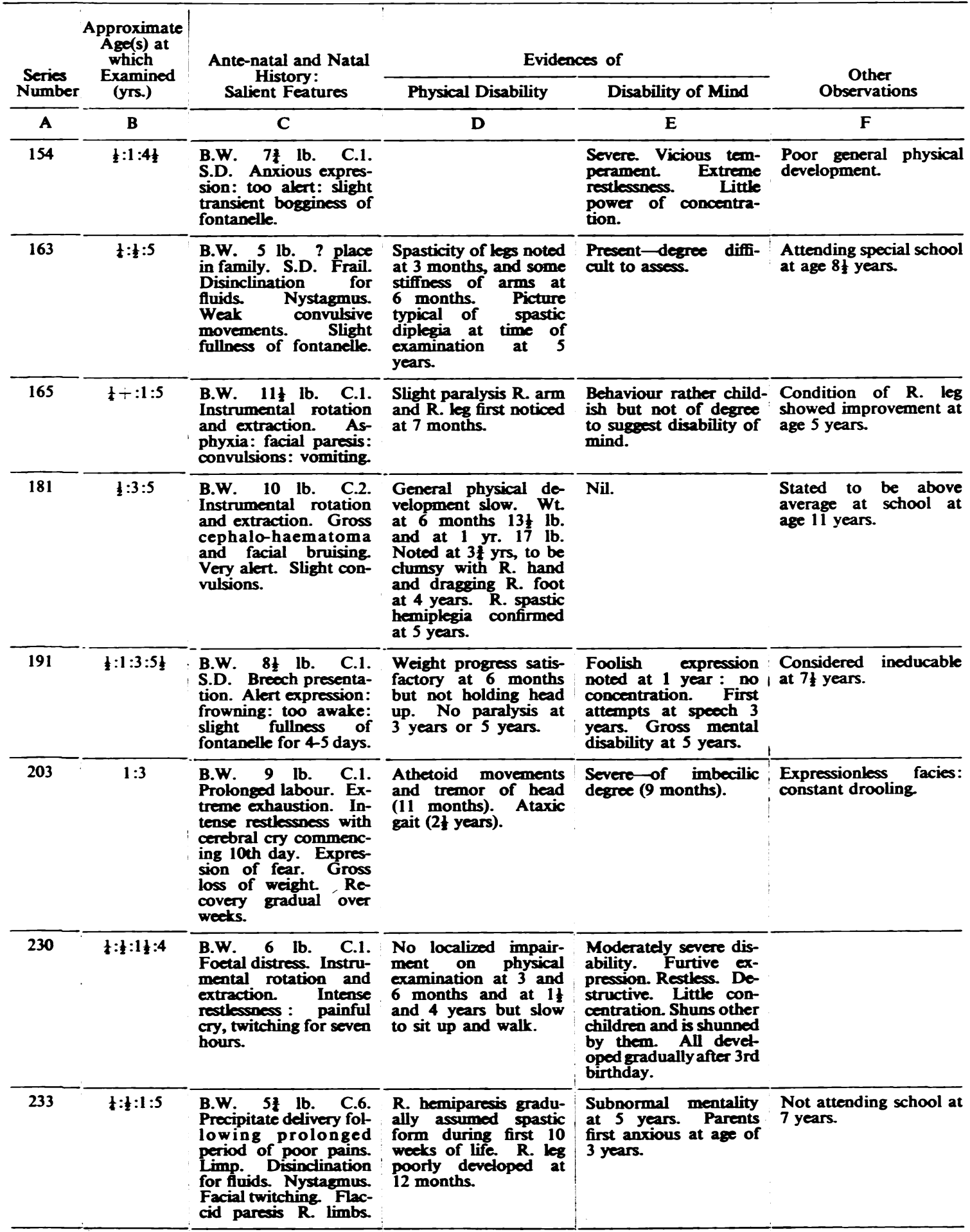

S.D. = Spontaneous delivery. C.S. = Caesarean section 


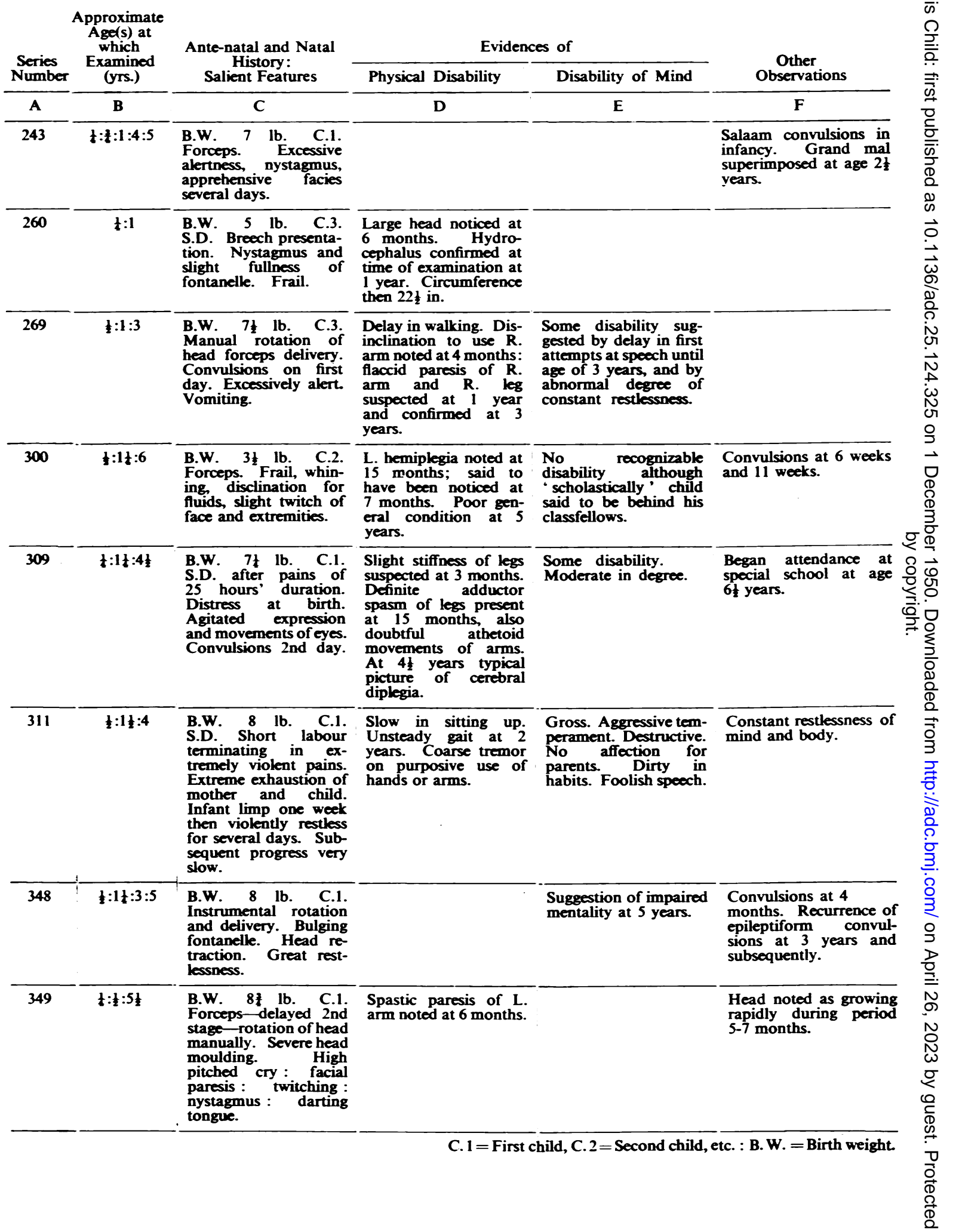




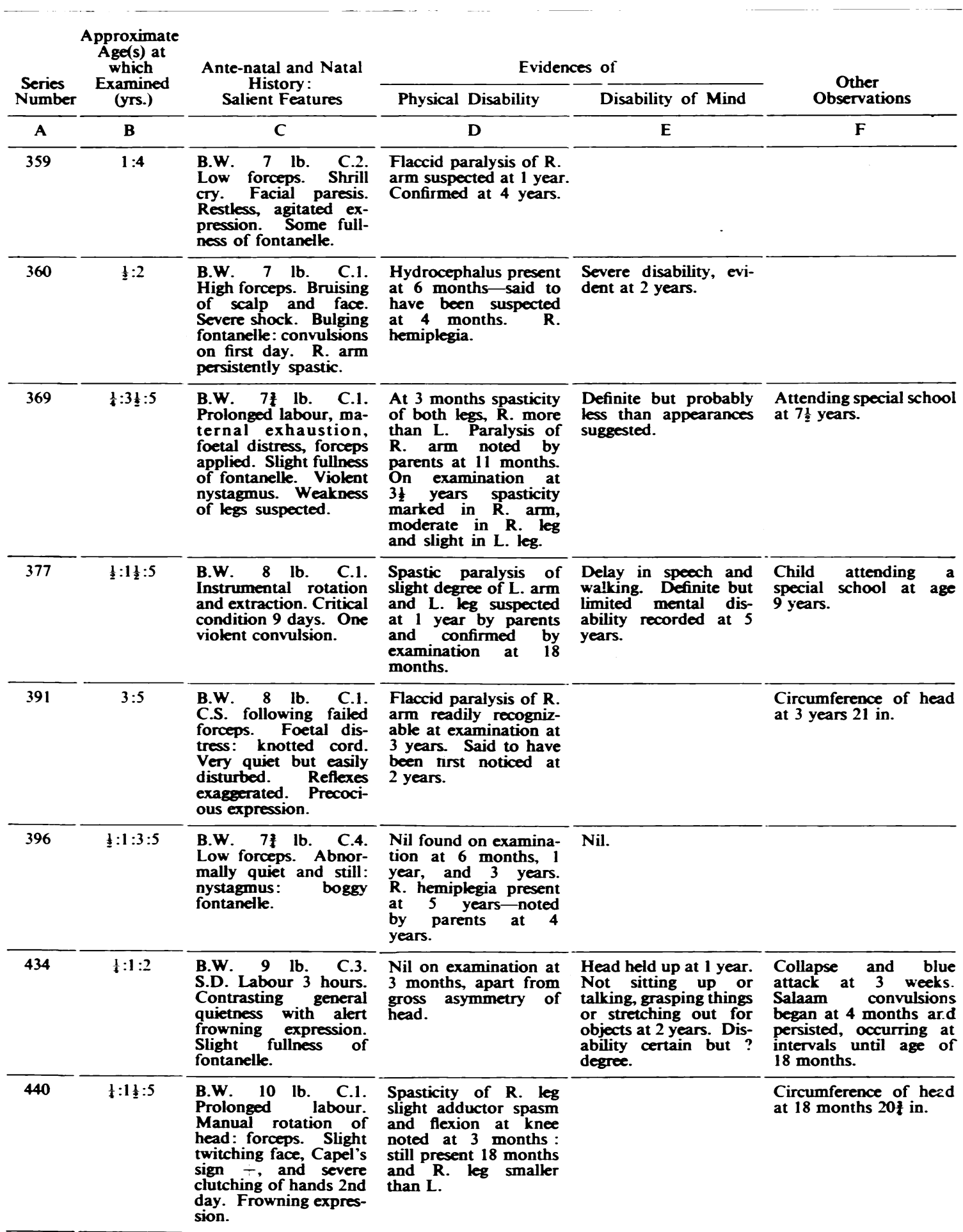

S. D. $=$ Spontaneous delivery. C. . $=$ Caesarean section. 


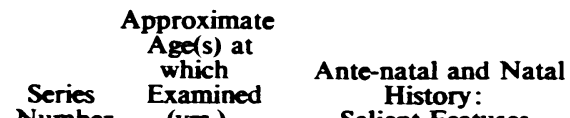

\begin{tabular}{|c|c|c|}
\hline $\begin{array}{l}\text { Series } \\
\text { Number }\end{array}$ & $\begin{array}{c}\text { Examined } \\
\text { (yrs.) }\end{array}$ & $\begin{array}{l}\text { History: } \\
\text { Salient Features }\end{array}$ \\
\hline $\mathbf{A}$ & B & C \\
\hline 443 & $1: 3: 3: 5$ & $\begin{array}{l}\text { B.W. } 4 t \text { lb. C.2. } \\
\text { S.D. Breech presenta- } \\
\text { tion. Frail and whin- } \\
\text { ing. Twitching of L. } \\
\text { face and L. leg. }\end{array}$ \\
\hline
\end{tabular}

\begin{tabular}{ll}
\hline 448 & \multicolumn{1}{|c|}{$\begin{array}{l}\text { B.W. 5 lb. C.1. } \\
\text { Forceps delivery-? } \\
\text { indication. Noticeably } \\
\text { limp at birth. Dis- } \\
\text { inclined fluids. Full- } \\
\text { ness without tension } \\
\text { of fontanelle. Facial } \\
\text { twitching. }\end{array}$} \\
\hline 470 & $\begin{array}{l}\text { B.W. 4 lb. C.3. } \\
\text { S.D. Limp at birth. }\end{array}$ \\
& $\begin{array}{l}\text { For } 7 \text { days no inclina- } \\
\text { tion fluids. Fluctuating } \\
\text { cyanosis. Occasional } \\
\text { twitching of face and } \\
\text { R. limbs. }\end{array}$ \\
\end{tabular}

481 3:3:5 B.W. 81 lb C.1
Prolonged labour despite good pains. Foetal distress. S.D. Limp and exhausted some days after birth. Great restlessness and apparent pain on 9th day. Thereafter slow improvement over weeks.

\begin{tabular}{|c|c|c|}
\hline 483 & $\frac{1}{2}: 1: 4 \frac{1}{2}$ & $\begin{array}{l}\text { B.W. } 7 \frac{1}{2} \text { lb. C.1. } \\
\text { S. D. Breech presenta- } \\
\text { tion. Too alert: anxious } \\
\text { facies, etc., in early days. } \\
\text { Twitching of hands. }\end{array}$ \\
\hline 484 & $1: 1\}$ & $\begin{array}{l}\text { B.W. } 11 \frac{1}{2} \text { lb. C.5. } \\
\text { S.D. before arrival of } \\
\text { midwife. Mild asphy- } \\
\text { xia. Wakeful, restless, } \\
\text { frowning and full } \\
\text { fontanelle for four } \\
\text { days. }\end{array}$ \\
\hline
\end{tabular}

\begin{tabular}{|c|c|c|}
\hline 490 & $\frac{1}{2}: 3$ & $\begin{array}{l}\text { B.W. } 61 \text { lb. C.1. } \\
\text { S.D. precipitate : no } \\
\text { doctor or midwife in } \\
\text { attendance. Weak } \\
\text { generalized convul- } \\
\text { sions on arrival of } \\
\text { doctor. }\end{array}$ \\
\hline
\end{tabular}

\begin{tabular}{|c|c|c|}
\hline 504 & $\frac{1}{2}: 1 \frac{1}{4}: 3$ & $\begin{array}{l}\text { B.W. } 7 \frac{1}{2} \text { lb. C.1. } \\
\text { High forceps. Double } \\
\text { cephalo - hacmatoma. } \\
\text { Bruised face. Slight } \\
\text { convulsions first day. }\end{array}$ \\
\hline
\end{tabular}

Evidences of

\begin{tabular}{|c|c|c|}
\hline Physical Disability & Disability of Mind & $\begin{array}{c}\text { Other } \\
\text { Observations }\end{array}$ \\
\hline D & $\mathbf{E}$ & $\mathbf{F}$ \\
\hline $\begin{array}{l}\text { Limited movement of } \\
\text { L. limbs at } 3 \text { months. } \\
\text { Spastic paralysis of } L \text {. } \\
\text { arm and limited move- }\end{array}$ & Nil at 5 years. & $\begin{array}{l}\text { Hydrocephalus sus- } \\
\text { pected at } 3 \text { months but } \\
\text { not confirmed at sub- } \\
\text { sequent examinations. }\end{array}$ \\
\hline
\end{tabular}

ment of $L$. leg at 9 months. Some improvement of $\mathrm{L}$. leg at 3 years.

Spasticity of $R$. leg

Gross.

Convulsions at 3 years.

and $R$. arm suspected

3 months and tentative diagnosis of hemiplegia made. Next seen at 4 years when clinical picture that of spastic diplegia.

Slight flaccid paresis
of legs suspected when discharged from hospital at 8 weeks: on examination at 6 months paralysis. $\mathbf{R}$. leg more than L. At 3 years spastic $R$. arm.

Obvious disability at time of examination at 3 years.

Observed at 6 months on account of ? hydrocephalus not confirmed at later examinations. Convulsions occurred at 8 years.

Impaired coordination in use of arms and limbs but no true ataxia. Vague suggestion of athetoid movements involving arms (3 years). Nystagmus (11 months).

Moderate but definite retardation. Speech babyish at 5 years. Foolish expression. No interest in other children. Habits unclean. Restless behaviour.

Markedly obese: weight $54 \mathrm{lb}$. at 5 years.

Delay in sitting up and standing.

Moderately severe disability. Unintelligible speech. Unclean and destructive habits.

Nil found on examination at 3 months. Not sitting up or saying words at 15 months.

Pronounced restlessness of mind and body: no evidence of will ? convulsions at age to concentrate; does not recognize mother: rather strange facial expression. Almost certainly mental disability present.
Weight at 6 months 11 lb. Not sitting up at 7 months. Slight flaccid paralysis of $L$. limbs suspected by parents at 21 years and confirmed on examination at 3 years.

Nil on examination at 6 and 15 months. R. hemiplegia most marked in arm at examination at 3 years.
Nil.

Salaam convulsions in infancy. Major epileptiform attack at 15 months. 


\begin{tabular}{|c|c|c|c|c|c|}
\hline \multirow{2}{*}{$\begin{array}{l}\text { Series } \\
\text { Number. }\end{array}$} & \multirow{2}{*}{$\begin{array}{c}\text { Approximate } \\
\text { Age(s) at } \\
\text { which } \\
\text { Examined } \\
\text { (yrs.) }\end{array}$} & \multirow{2}{*}{$\begin{array}{c}\text { Ante-natal and Natal } \\
\text { History: } \\
\text { Salient Features }\end{array}$} & \multicolumn{2}{|c|}{ Evidences of } & \multirow{2}{*}{$\begin{array}{l}\text { Other } \\
\text { Observations }\end{array}$} \\
\hline & & & Physical Disability & Disability of Mind & \\
\hline $\mathbf{A}$ & B & $\mathbf{C}$ & D & $\mathbf{E}$ & $\mathbf{F}$ \\
\hline 546 & $1: 1: 3: 5$ & $\begin{array}{l}\text { B.W. } 9 \frac{1}{2} \text { lb. C.2. } \\
\text { Breech delivery-in- } \\
\text { strumental. Asphyxia: } \\
\text { bruising. Full fontan- } \\
\text { dle. Darting move- } \\
\text { ments of eyes. Cerebral } \\
\text { cry. }\end{array}$ & $\begin{array}{l}\text { Spastic paresis of L. } \\
\text { leg suspected at } 3 \text { and } \\
\text { confirmed at } 5 \text { months. }\end{array}$ & $\begin{array}{l}\text { Delay in sitting up } \\
\text { and talking. Leeway } \\
\text { subsequently made up } \\
\text { but child babyish at } \\
5 \text { years. }\end{array}$ & $\begin{array}{l}\text { Mother stated head } \\
\text { growing very balloon- } \\
\text { like and large at } 5 \\
\text { months. Circumference } \\
\text { at } 6 \text { months } 17 \text { in. and } \\
\text { at } 5 \text { years } 21 \text { in. }\end{array}$ \\
\hline 549 & $\frac{1}{2}: 1: 4$ & $\begin{array}{l}\text { B.W. } 4 \text { lb. C.1. } \\
\text { S.D. Breech presenta- } \\
\text { tion. Frail at birth : } \\
\text { disinclined for fluids : } \\
\text { transient twitching of } \\
\text { face and extremities. }\end{array}$ & $\begin{array}{l}\text { Physical progress satis- } \\
\text { factory until age } 16 \\
\text { months. Weight at } \\
1 \text { year } 18 \text { lb. Left } \\
\text { with flaccid paresis } \\
\text { of L. arm after last } \\
\text { series of convul- } \\
\text { sions. }\end{array}$ & & $\begin{array}{l}\text { Convulsions at } 3,9 \text {, } \\
\text { and } 16 \text { months without } \\
\text { evidence of refiex stimu- } \\
\text { lating factor. }\end{array}$ \\
\hline 580 & $\frac{1}{2}: 1 t: 5$ & $\begin{array}{l}\text { B.W. } 8 \text { lb. C.1. } \\
\text { Forceps. } \\
\text { Laceration } \\
\text { of scalp. Asphyxia. } \\
\text { Alert. Bogsy fontan- } \\
\text { elle. }\end{array}$ & $\begin{array}{l}\text { General physical pro- } \\
\text { gress good. Disinclina- } \\
\text { tion to use R. leg and } \\
\mathbf{R} \text {. arm noted at } 10 \\
\text { months. } R \text {. hemi- } \\
\text { plegia confirmed at } 15 \\
\text { months. }\end{array}$ & Nil. & \\
\hline 590 & $\frac{1}{2}: 3: 5$ & $\begin{array}{l}\text { B.W. } 7 \text { lb. C.4. } \\
\text { Prolonged labour: } \\
\text { elderly mother: foetal } \\
\text { distress. Asphyxia : } \\
\text { convulsions and cere- } \\
\text { bral cry. Full fontan- } \\
\text { elle. }\end{array}$ & $\begin{array}{l}\text { Spastic paralysis of } \\
\text { R. arm and L. arm } \\
\text { noted at } 2 \text { months } \\
\text { (in hospital). Present } \\
\text { at } 3 \text { years together } \\
\text { with slight flaccid } \\
\text { paresis of } R \text {. leg. }\end{array}$ & $\begin{array}{l}\text { Rather dull child at } \\
5 \text { years but not neces- } \\
\text { sarily mental disability } \\
\text { as such. }\end{array}$ & \\
\hline 611 & $t: \frac{1}{2}: 1 \frac{1}{2}$ & $\begin{array}{l}\text { B.W. } 6 \text { lb. C.4. } \\
\text { S.D. Labour } 5 \text { hours. } \\
\text { Nystagmus. Feeble } \\
\text { twitching movements. } \\
\text { Frail condition. }\end{array}$ & $\begin{array}{l}\text { Pronounced enlarge- } \\
\text { ment of head at } 3 \\
\text { months. Spasticity and } \\
\text { wasting of L. arm. } \\
\text { Spastic L. leg. Prob- } \\
\text { ably blind. }\end{array}$ & & Died at age 19 months. \\
\hline 618 & $\frac{1}{2}: 11: 6$ & $\begin{array}{l}\text { B.W. } 13 \text { lb. C.1. } \\
\text { Instruments. Aong } \\
\text { labour. Asphyxia. } \\
\text { Restless. Slight con- } \\
\text { vulsion 2nd day. }\end{array}$ & $\begin{array}{l}\text { Uninterrupted progress } \\
\text { until about } 2 \text { years of } \\
\text { age when paresis of } \\
R \text {. leg noticed. On } \\
\text { examination marked } \\
\text { flaccid paresis of } \\
R \text {. leg and slight } \\
\text { flaccid paresis of } R \text {. } \\
\text { arm. }\end{array}$ & Nil. & $\begin{array}{l}\text { Convulsions at age } 2 \frac{1}{2} \\
\text { years. }\end{array}$ \\
\hline 670 & $\frac{1}{2}: 3$ & $\begin{array}{l}\text { B.W. } 5 \text { lb. C.5. } \\
\text { S.D. rather rapid } \\
\text { delivery. Weak. Dis- } \\
\text { inclination for fluids. } \\
\text { R. facial paresis. Weak } \\
\text { convulsions. }\end{array}$ & $\begin{array}{l}\text { Weight at } 6 \text { months } \\
9 \frac{1}{2} \text { lb.: general con- } \\
\text { dition reasonable. } \\
\text { Stiffness of } R \text {. arm } \\
\text { suspected at } 13 \\
\text { months and impaired } \\
\text { use of } R \text {. leg at } 20 \\
\text { months. } R \text {. spastic } \\
\text { hemiplegia present at } \\
3 \text { years. }\end{array}$ & $\begin{array}{l}\text { Doubtful-if present, } \\
\text { slight. }\end{array}$ & $\begin{array}{l}\text { Suspected hydrocepha- } \\
\text { lus at } 6 \text { months but } \\
\text { no confirmatory find- } \\
\text { ings at } 3 \text { years. }\end{array}$ \\
\hline
\end{tabular}

S. D. = Spontaneous delivery. C.S. = Caesarean section 


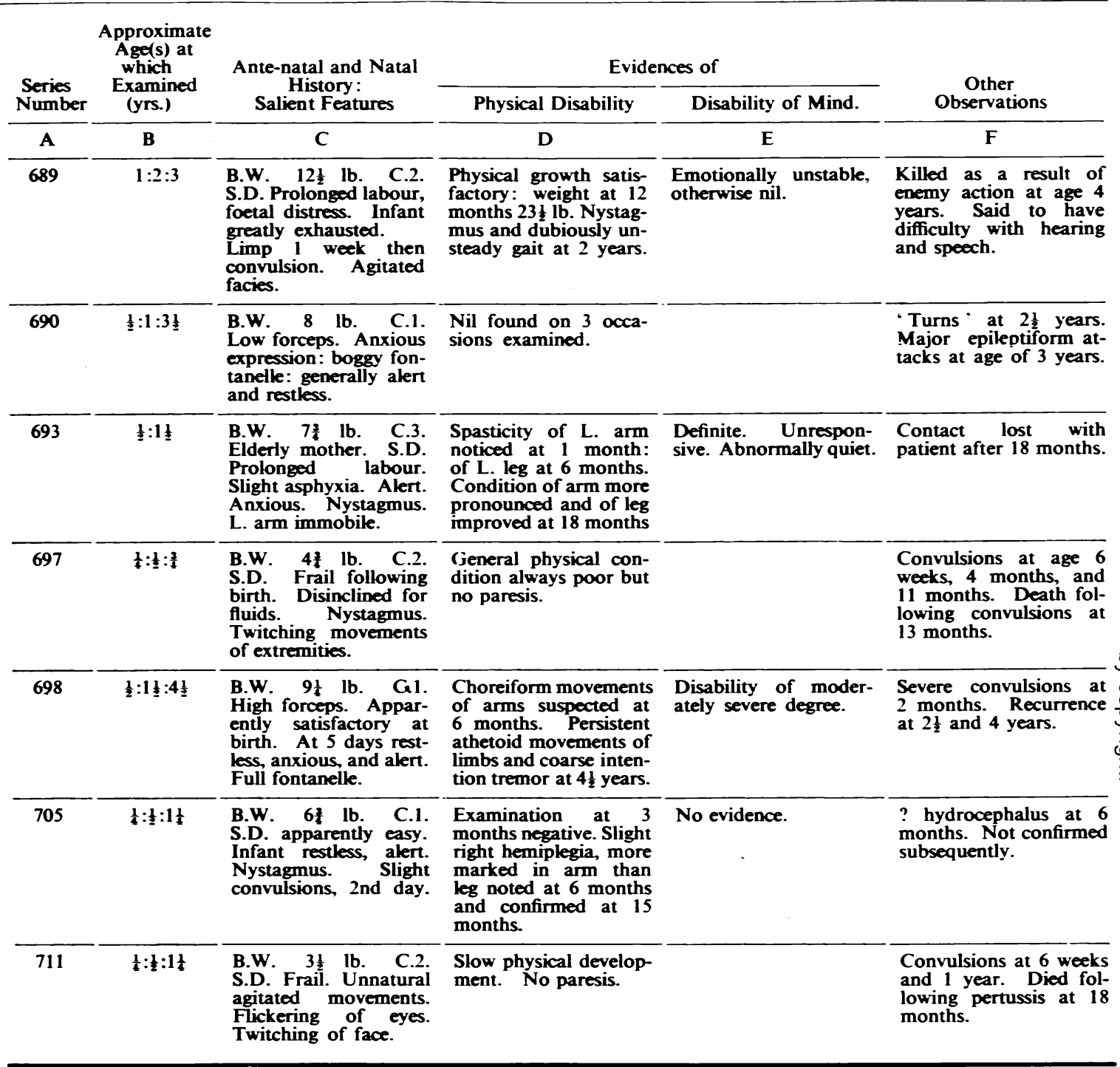

C. 1 = First child, C. 2 = Second child, etc. : B. W. = Birth weight. $\quad$ S. D. = Spontaneous delivery.

C.S. $=$ Caesarean section. 